\title{
Roles of SNARE Proteins and Synaptotagmin I in Synaptic Transmission: Studies at the Drosophila Neuromuscular Synapse
}

\author{
Yoshi Kidokoro \\ Institute for Behavioral Sciences, Gunma University School of Medicine, Maebashi, J apan
}

\section{Key Words}

Synaptic transmission - SNARE complex .

Synaptobrevin · Syntaxin · SNAP-25 · Synaptotagmin

\begin{abstract}
The roles of SNARE proteins, i.e. neuronal Synaptobrevin (n-Syb), SNAP-25 and Syntaxin 1A (Syx 1A), and Synaptotagmin I (Syt I) in synaptic transmission have been studied in situ using mutant embryos or larvae that lack these molecules or have alterations in them. Because of the ease of genetic manipulation, the Drosophila neuromuscular synapse is widely used for these studies. The functional properties of synaptic transmission have been studied in mutant embryos using the patchclamp technique, and in larvae by recording with microelectrodes. A major vesicular membrane protein, nSyb, is indispensable for nerve-evoked synaptic transmission. Spontaneous synaptic currents (minis), however, are present even in embryos totally lacking n-Syb (n-syb). Furthermore, Ca2t-independent enhancement of mini frequency induced by hypertonic sucrose solutions (hypertonicity response) is totally absent in n-syb. Embryos that have defects in SNAP-25 (SNAP-25) have similar but milder phenotypes than n-syb. The phenotype in synaptic transmission was most severe in the synapse lacking Syx 1A. Neither nerve-evoked synaptic currents nor minis occur in embryos lacking Syx 1A (syx 1A). No
\end{abstract}

hypertonicity response was observed in them. Syt I binds $\mathrm{Ca}^{2+}$ in vitro and probably serves as a $\mathrm{Ca}^{2+}$ sensor for nerve-evoked synaptic transmission, since nerveevoked synaptic currents were greatly reduced in embryos lacking Syt I (syt I). Also, Syt I has a role in vesicle recycling. Interestingly, the $\mathrm{Ca}^{2+-i n d e p e n d e n t ~ h y p e r t o n-~}$ icity response is also greatly reduced in syt $\mathrm{I}$. Minis persist in mutant embryos lacking any of these proteins ( $n$ Syb, SNAP-25 and Syt I), except Syx, suggesting that minis have a distinct fusion mechanism from that for fast and synchronized release. It appears that these SNARE proteins and Syt I are coordinated for fast vesicle fusion. Minis, on the other hand, do not require SNARE complex nor Syt I, but Syx is absolutely required for vesicle fusion. The SNARE complex and Syt I are indispensable for the hypertonicity response. None of these molecules seem to serve for selective docking of synaptic vesicles to the release site. For further studies on synaptic transmission, the Drosophila neuromuscular synapse will continue to be a useful model.

Copyright $\odot 2003$ S. Karger AG, Basel

\section{Introduction}

In the brain, information is processed at the synapses, and the malleability of synapses (synaptic plasticity) is generally believed to be the basis for memory and learn-

\begin{tabular}{ll}
\hline KARGER & ( 2003 S. Karger AG, Basel \\
Fax +4161306 1234 $34-862 X / 03 / 0121-0013 \$ 19.50 / 0$ \\
$\begin{array}{l}\text { E-Mail karger@karger.ch } \\
\text { www.karger.com }\end{array}$ & $\begin{array}{l}\text { Accessible online at: } \\
\text { www.karger.com/nsg }\end{array}$
\end{tabular}

Yoshi Kidokoro

Institute for Behavioral Sciences, Gunma University School of Medicine 3-39-22 Showa-machi

Maebashi 371-8511 (Japan)

Tel. +81 27220 8040, Fax +81 27220 8046, E-Mail kidokoro@med.gunma-u.ac.jp 
ing. To understand the molecular mechanism of synaptic plasticity, extensive studies in the mammalian brain are being conducted, and a variety of distinct mechanisms have been demonstrated to be involved [1, 2]. It appears that at different types of synapses, different mechanisms underlie synaptic plasticity. In principle, the efficacy of synaptic transmission could be modulated at any of the steps that lead to synaptic vesicle fusion, release of transmitter and activation of postsynaptic receptor channels. It is, then, important to thoroughly elucidate the basic mechanism of synaptic transmission to ultimately understand synaptic plasticity.

Currently, the SNARE hypothesis is a leading theory for synaptic vesicle fusion in the presynaptic terminal [3, 4]. Three key proteins, neuronal Synaptobrevin (n-Syb; also known as vesicle-associated membrane protein, VAMP), Syntaxin 1A (Syx 1A) and SNAP-25 (synaptosome-associated protein of $25 \mathrm{kD}$ ), form the core of the SNARE complex, which is thought to be essential for $\mathrm{Ca}^{2+}$-dependent fast synaptic vesicle fusion. (By convention, the names of Drosophila proteins are capitalized and the names of mutants and genes are italicized.) In addition, Synaptotagmin I (Syt I) is considered to be a major $\mathrm{Ca}^{2+}$ sensor that is coupled to the SNARE complex for detection of a transient $\mathrm{Ca}^{2+}$ rise. In this article, I shall review functional defects of synaptic transmission mainly in mutant Drosophila embryos that lack these major proteins or have defects in one of them. In all these mutants, synaptic transmission is severely impaired, but the details of defects are different, which might give us a clue to understanding the differential roles of these key proteins in synaptic transmission.

The Drosophila neuromuscular synapse is a simple model that can provide us with unique features for studies of synaptic transmission and is accessible with patchclamp techniques even in the early stages of synapse formation [5-9]. Our knowledge of the embryonic Drosophila neuromuscular synapse is rapidly expanding, and its characteristic properties are being elucidated. At the same time, some discrepancies among findings in various reports are surfacing. For further advancement of this field, it is necessary to critically evaluate those findings reported in the literature and to come up with a coherent picture of the characteristics of synaptic transmission in each mutant. Also, I shall compare some aspects of defects in synaptic transmission in Drosophila embryos and larvae with those in other animals to reveal a common feature of a particular mutation among species.

The specialization of the presynaptic nerve terminal for fast exocytosis has been widely investigated. It is pos- tulated that molecules on the synaptic vesicle membrane specifically bind to the receptors on the presynaptic membrane and form a docked/primed state. Upon arrival of an action potential at the presynaptic nerve terminal at the release site and the resulting entry of $\mathrm{Ca}^{2+}$ through voltage-gated $\mathrm{Ca}^{2+}$ channels, the local concentration of $\mathrm{Ca}^{2+}$ rises abruptly to a sub-millimolar level [10-12]. This high concentration of $\mathrm{Ca}^{2+}$ is detected by a low-affinity $\mathrm{Ca}^{2+}$ sensor on the vesicular membrane, which initiates rapid membrane fusion, resulting in synchronous transmitter release. On the other hand, spontaneous fusion of synaptic vesicles in the resting state generates miniature synaptic potentials (minis). These events occur at lower cytosolic $\mathrm{Ca}^{2+}$ concentrations, and minis have been observed even in the absence of external $\mathrm{Ca}^{2+}$ [13]. Thus, synchronized $\mathrm{Ca}^{2+}$ entry through voltage-gated $\mathrm{Ca}^{2+}$ channels is not required for minis. The frequency of these quantal events, however, changes when the cytosolic $\mathrm{Ca}^{2+}$ concentration enters the micromolar range [14]. Therefore, requirements for these two types of transmitter release, namely action-potential-triggered synaptic currents and minis, may be different.

\section{Neuronal Synaptobrevin}

$\mathrm{n}$-Syb is a major protein on the vesicular membrane and the target of tetanus toxin. Since tetanus toxin poisoning is fatal for animals, n-Syb was suspected to play an important role in synaptic transmission.

\section{Nerve-Evoked Synaptic Currents}

In an elegant experiment expressing a gene encoding tetanus toxin light chain in the presynaptic terminal, Sweeney et al. [15] showed that nerve stimulation no longer evoked synaptic currents at the embryonic Drosophila neuromuscular synapse, but minis remained. These findings were confirmed in mutants with a genetic deletion of the $n-s y b$ locus eliminating expression of $\mathrm{n}-\mathrm{Syb}\left(n-s y b^{\text {null }}\right.$; fig. 1) $[16,17]$. Multiple steps are involved in nerveevoked synaptic currents between the influx of $\mathrm{Ca}^{2+}$ during an action potential and final vesicular fusion. A defect in any of these steps leads to a failure of synaptic transmission. Can the absence of a response to an action potential in $n-s y b^{\text {null }}$ be attributed to defective function of the voltage-gated $\mathrm{Ca}^{2+}$ channels? That does not seem to be the case, because repetitive nerve stimulation increased the frequency of minis in $n-s y b^{\text {null }}$ embryos, suggesting that $\mathrm{Ca}^{2+}$ influx does occur during an action potential. Furthermore, significantly more quantal transmitter release 
Fig. 1. Nerve-evoked synaptic currents are absent from the neuromuscular junctions of $n$-syb mutant embryos. Evoked currents are lacking in $n$-syb $b^{\text {null }}$ mutants, $n-s y b^{\Delta \mathrm{F} 33 \mathrm{~B}}(\mathbf{A})$ and $n-s y b^{\mathrm{F} 33-\mathrm{R}}(\mathbf{B})$, but are present in the parental control, line 34 (C). The external solution contained $2 \mathrm{mM} \mathrm{Ca}^{2+}$ for lines $n-s y b^{\Delta \mathrm{F} 33 \mathrm{~B}}$ and $n-s y b^{\mathrm{F} 33-\mathrm{R}}$ and $0.5 \mathrm{~m} M$ for line 34. Reproduced from Deitcher et al. [16] with permission.

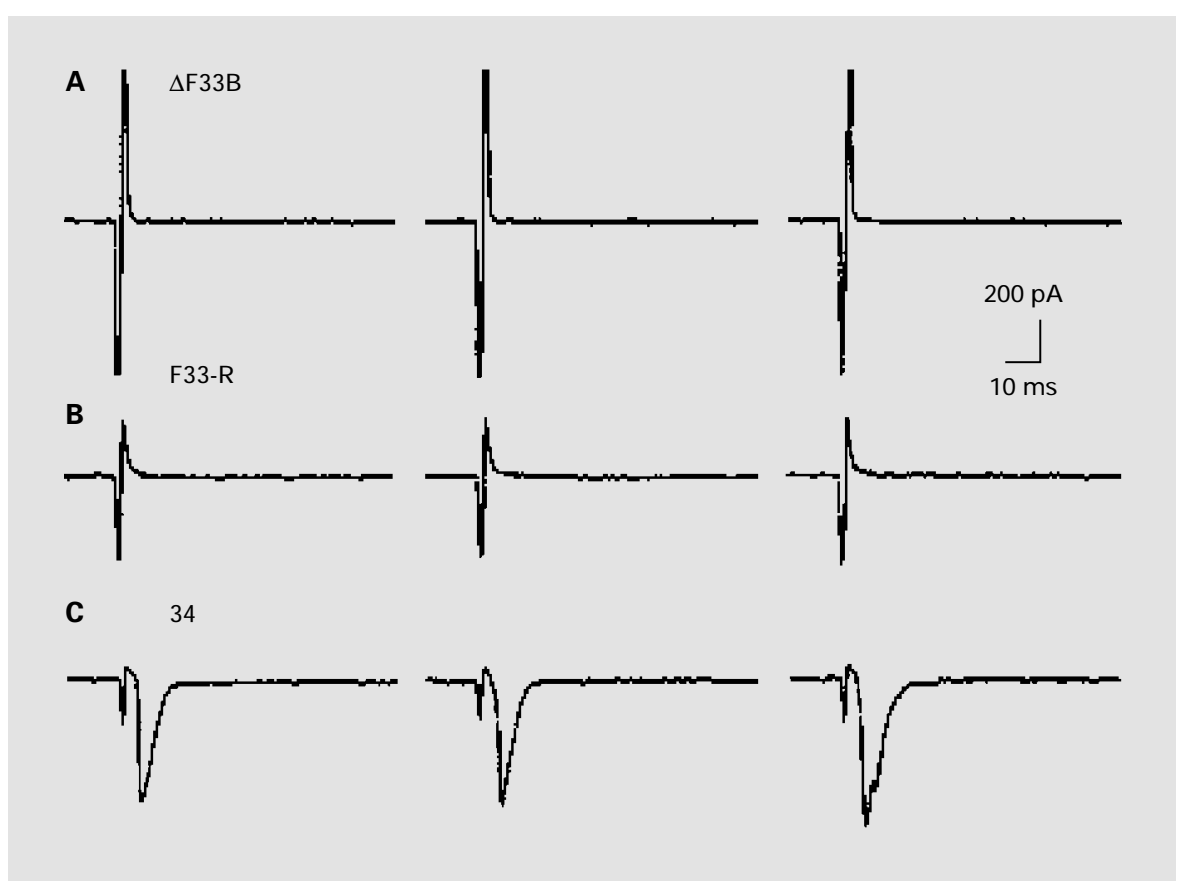

occurred shortly after stimulation, indicating that $\mathrm{Ca}^{2+}$ entered at the right time (fig. 2). These findings suggest that quantal transmitter release in $n$-sybull embryos is $\mathrm{Ca}^{2+}$ dependent, which was verified as described below, but transient $\mathrm{Ca}^{2+}$ influx during an action potential does not trigger efficient vesicle fusion in $n-s y b^{\text {null }}$ mutant embryos.

\section{Miniature Synaptic Currents}

Although nerve-evoked synaptic currents were observed neither in the tetanus toxin-expressing transformant nor in $n$-sy $b^{\text {null }}$ embryos, minis were readily detected [15-18]. The frequency of minis was reduced in the embryos expressing tetanus toxin light chain to approximately half of that in the control. This phenotype raised questions concerning the nature of the residual quantal release of transmitter. Does the remaining release represent the persistence of the constitutive membrane trafficking pathway that moves vesicles to the surface in an unregulated manner? That does not seem to be the case, because the frequency of minis in $n$-sy $b^{\text {null }}$ mutants, although about one third of that in controls, is dependent on external $\mathrm{Ca}^{2+}$, and their amplitudes are not different from those in controls, suggesting that vesicle release occurs at the right site facing the postsynaptic membrane with a high receptor density (fig. 3) [17]. Indeed, iontophoretic application of glutamate directly onto the postsy- naptic membrane in the tetanus toxin-expressing transformant induced inward currents similar to those in wildtype embryos [18]. Similarly, in $n$-syb $b^{\text {null }}$ embryos, puff application of glutamate induced inward currents similar to those in controls [19]. These results indicate that receptors are clustered at the postsynaptic membrane, and vesicular release occurs at the right site as it takes place during normal synaptic transmission.

Treatments that produce sustained elevation of cytosolic $\mathrm{Ca}^{2+}$, such as high $\mathrm{K}^{+}$treatment in the presence of external $\mathrm{Ca}^{2+}$ or application of a $\mathrm{Ca}^{2+}$ ionophore, induced an increase of the mini frequency in $n-s y b^{\text {null }}$ embryos [17]. Therefore, it appears that an elevation of intracellu$\operatorname{lar} \mathrm{Ca}^{2+}\left(\left[\mathrm{Ca}^{2+}\right]_{\mathrm{i}}\right)$ is sensed by the vesicle fusion machinery in the absence of $n-s y b$. However, the ability of vesicles to respond to a fast, transient increase in $\left[\mathrm{Ca}^{2+}\right]_{i}$ is specifically defective in this mutant. Syt I is considered to be a major $\mathrm{Ca}^{2+}$ sensor for nerve-evoked synaptic transmission. As will be discussed below, the phenotype of syt Inull mutants $\left(s y t^{\text {null }}\right)$ in synaptic transmission is less severe than that in $n$-syb $b^{\text {null }}$ embryos. Nerve-evoked synaptic transmission remained even though the sensitivity to external $\mathrm{Ca}^{2+}$ was very much reduced in $s y t^{\text {tull }}$ embryos, and minis also remained. The mini frequency is sensitive to external $\mathrm{Ca}^{2+}[20]$. Thus, $\mathrm{n}-\mathrm{Syb}$ and Syt I are required for nerve-induced synaptic transmission but are not necessary for minis. 

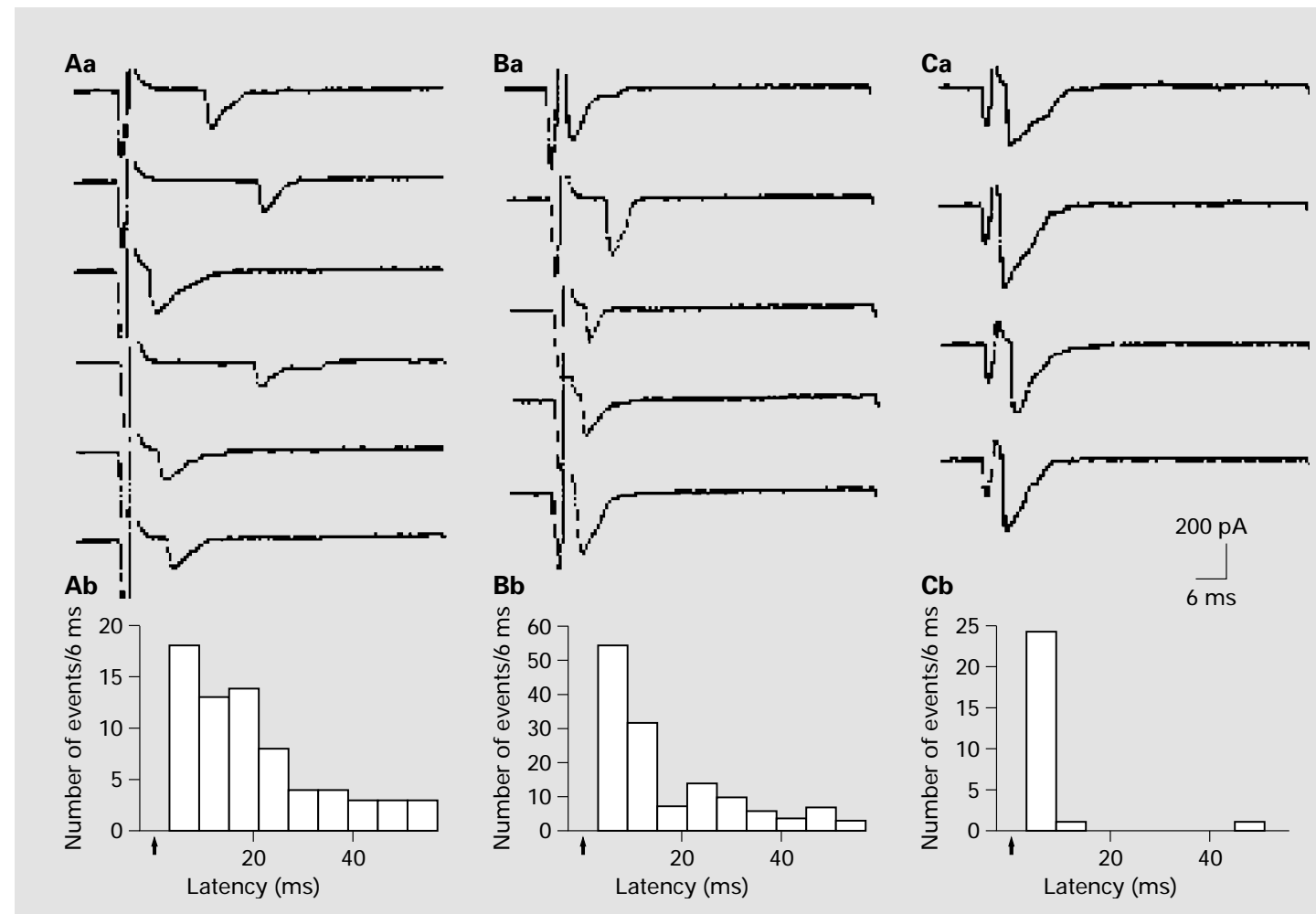

Fig. 2. Loosely synchronous release of transmitter in an $n$-sy $b^{\Delta \mathrm{F} 33 \mathrm{~B}}$ \left. embryo in $2{\mathrm{~m} M \mathrm{Ca}^{2+}}^{2+} \mathbf{A a}, \mathbf{A b}\right)$ and in an $n-s y b^{\mathrm{F} 33-\mathrm{R}}$ embryo in $2 \mathrm{~m} M$ $\mathrm{Ca}^{2+}(\mathbf{B a}, \mathbf{B b})$, and synchronous release in a line 34 larva in $0.2 \mathrm{mM}$ $\mathrm{Ca}^{2+}(\mathbf{C a}, \mathbf{C b})$. Aa Sample traces during tetanic stimulation that had synaptic currents were selected. Ab The latency histogram of synaptic currents that occurred after 1,841 stimuli during tetanic stimulation. On the ordinate, the cumulative number of events belonging to a bin is plotted. The abscissa is aligned to the above sample traces.
Upward arrows indicate the stimulus onset. Ba Selected sample traces during tetanic stimulation. Bb The latency histogram was constructed out of synaptic currents that occurred after 792 stimuli during tetanic stimulation. Ca Sample traces that occurred during tetanic stimulation. $\mathbf{C b}$ The latency histogram was constructed out of synaptic currents that occurred after 1,094 stimuli during tetanic stimulation. Reproduced from Yoshihara et al. [17] with permission.

\section{Hypertonicity Response}

Another phenomenon characteristic of the transformant expressing tetanus toxin light chain or $n-s y b^{\text {null }}$ mutants is a total lack of an enhancing effect of hypertonicity $[21,22]$. The enhancing effect of hypertonicity on synaptic transmission was first described in 1952 by Fatt and Katz [23] at the frog neuromuscular synapse. An application of hypertonic solutions to the synapse increases the mini frequency. The hypertonicity response is robust in the absence of external $\mathrm{Ca}^{2+}$. Moreover, even when the $\mathrm{Ca}^{2+}$ concentration inside the presynaptic terminal is buffered at low levels by injection of a fast $\mathrm{Ca}^{2+}$ chelator, BAPTA, the hypertonicity response remains [24, 25]. The underlying mechanism for this response has long eluded our understanding. Recently, it has been shown that integrins mediate a part of this response at the frog

neuromuscular synapse [26], and this finding was further extended in experiments at the embryonic Drosophila neuromuscular synapse [27]. In the latter case, about two thirds of the hypertonicity response was mediated by integrins. Furthermore, the hypertonicity response was much smaller in a mutant lacking a major subunit of protein kinase A, DCO [28], and larger in a mutant, dunce, in which the cAMP level is high due to defective phosphodiesterase [29]. These results suggest that cAMP is involved in the hypertonicity response. It appears that the mechanical signal induced by hypertonicity is transmitted through the presynaptic membrane by integrins, which are probably positively coupled to adenylyl cyclase [27]. An elevation of cAMP in the terminal causes an increase in the mini frequency. Thus, the lack of response to cAMP in $n$-syb embryos [30] (described below) may explain a 


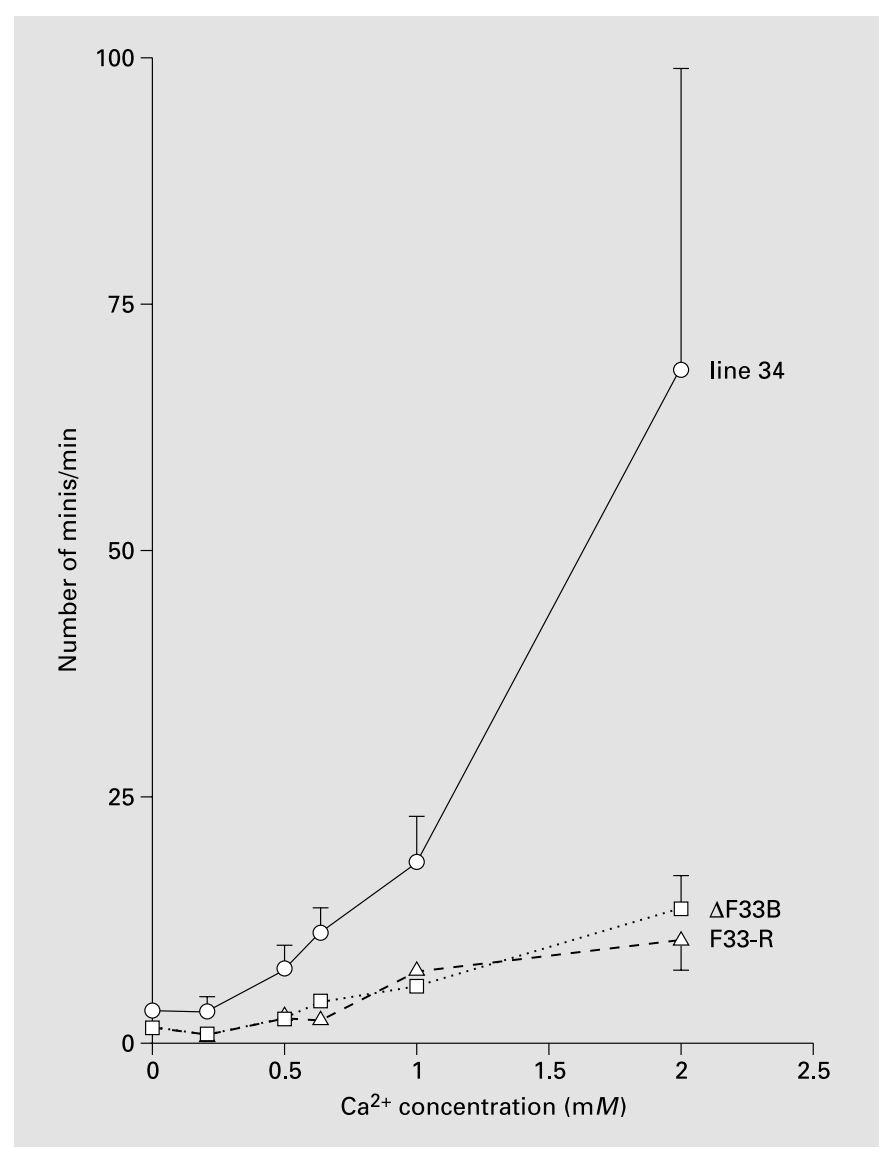

Fig. 3. The relation between the frequency of minis and external $\mathrm{Ca}^{2+}$ concentration in $20 \mathrm{mM} \mathrm{K} \mathrm{K}^{+}$solution in the presence of $3 \mu \mathrm{M}$ tetrodotoxin. The frequency was plotted against the external $\mathrm{Ca}^{2+}$ concentration. Reproduced from Yoshihara et al. [17] with permission.

part of this phenotype, but the total lack of hypertonicity response cannot be explained. The lack of hypertonicity response in $n-s y b$ suggests that it requires SNARE complex formation.

\section{Response to cAMP Elevation}

In wild-type 1st instar larvae and embryos, cAMP has been shown to increase the mini frequency in the absence of external $\mathrm{Ca}^{2+}[30,31]$. This response is a part of metabotropic glutamate receptor activation. When the presynaptic nerve fires repetitively, the glutamate released binds to presynaptic metabotropic glutamate receptors and increases cAMP in the presynaptic nerve terminal. Higher cAMP levels in the presynaptic terminal enhance synaptic transmission [31]. Interestingly, $n-s y b^{\text {null }}$ embryos totally lack the cAMP response [17]. It is not clear how this phe- nomenon is related to the lack of nerve-evoked synaptic transmission in $n-s y b^{\text {null }}$ embryos.

\section{Response to Black Widow Spider Venom}

Black widow spider venom is known to cause a massive release of transmitter in the presence of external $\mathrm{Ca}^{2+}$ by increasing internal $\mathrm{Ca}^{2+}$ concentrations [32]. Since an elevation of $\left[\mathrm{Ca}^{2+}\right]_{\mathrm{i}}$ by various methods increases mini frequencies, as described above, black widow spider venom was also expected to increase mini frequencies in $n$-sy $b^{\text {null }}$ embryos. To our surprise, in transformant embryos that express tetanus toxin light chain, Broadie et al. [18] observed no response to black widow spider venom even in the presence of $1 \mathrm{~m} M$ external $\mathrm{Ca}^{2+}$. In contrast, Deitcher et al. [16] observed reduced responses in $n$-sy $b^{\text {null }}$ embryos compared with those in wild-type embryos in the presence of $0.8 \mathrm{mM} \mathrm{Ca}{ }^{2+}$. The response was larger with $2 \mathrm{mM} \mathrm{Ca}{ }^{2+}$, indicating that the response is $\mathrm{Ca}^{2+}$ dependent. Black widow spider venom tends to lose its potency, which could be the reason for the negative result in the transformant expressing tetanus toxin light chain reported by Broadie et al. [18].

\section{A Homolog of n-syb, c-syb}

A homolog of $n-s y b$ is $c-s y b$, which is expressed ubiquitously at a low level in various tissues and most abundantly in the gut. cDNA for $n-s y b$ is $70 \%$ identical to that of $c$-syb $[33,34]$. It is thus possible that $c$-syb substitutes $n$ $s y b$ in the SNARE complex and supports minis in $n$-sy $b^{\text {null }}$ embryos. The phenotypes in $n-s y b^{\text {null }}$ embryos are very similar to the transformant expressing tetanus toxin light chain. Since tetanus toxin does not cleave the protein encoded by $c-s y b[15]$, in both cases, $c-s y b$ products stay intact, and the remaining synaptic function in $n-s y b^{\text {null }}$ embryos might be supported by $c-s y b$. It appears, however, that synaptic transmission in $n$-syb $b^{\text {null }}$ embryos is qualitatively different from that in wild-type embryos. Nerve-evoked synaptic transmission is completely missing $[16,17]$, and no enhancing hypertonicity response was observed [21,22]. If $c$-syb can substitute $n$-syb, it does so only for limited functions of $n-s y b$, such as in supporting spontaneous fusion of vesicles (minis).

\section{SNAP-25}

A temperature-sensitive paralytic Drosophila mutant of SNAP-25 was isolated, and synaptic transmission in 3rd instar larvae was studied $\left(S N A P-25^{\text {ts }}\right)$. This mutation is recessive and causes loss of function at non-permissive 

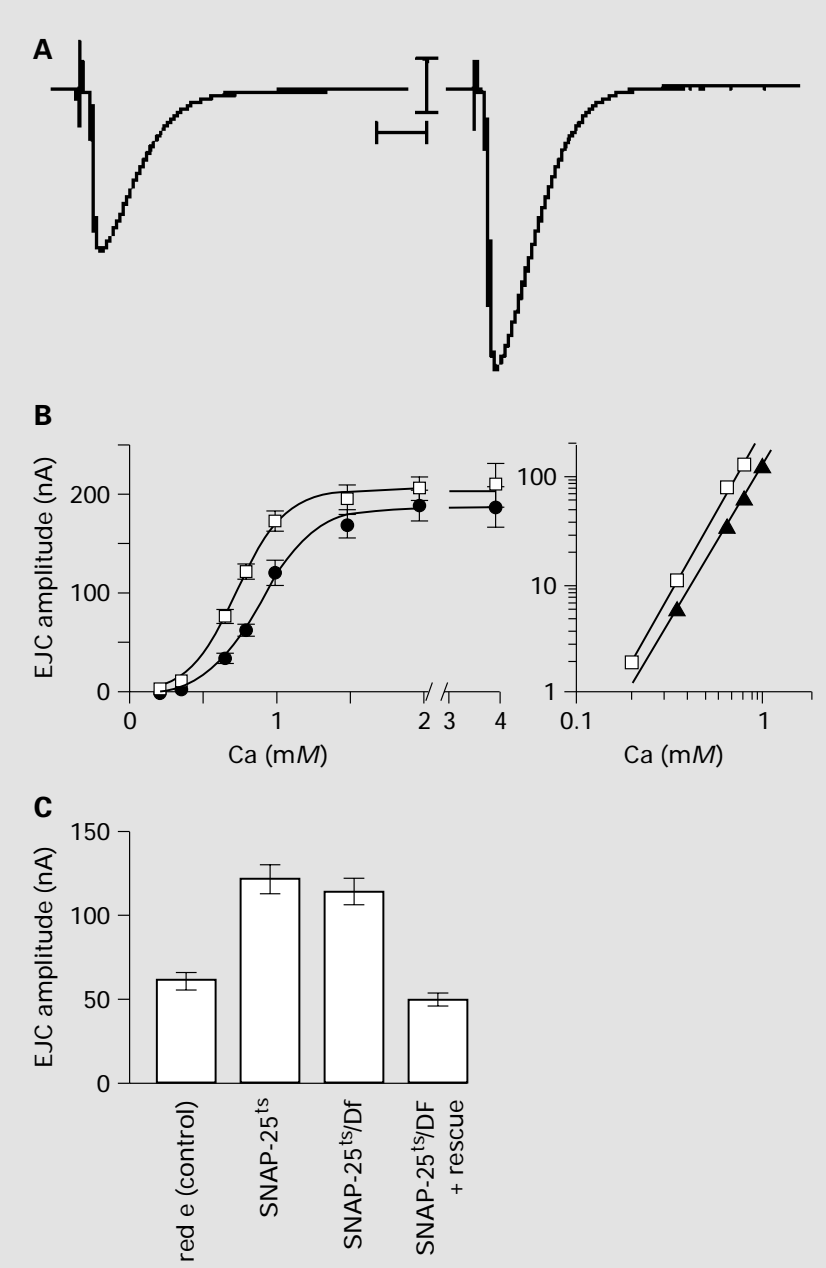

Fig. 4. Evoked release of neurotransmitter from red e (control) and $S N A P-25^{\text {ts }} 3$ rd instar larval neuromuscular junction at $22^{\circ} \mathrm{C}$. A Twoelectrode voltage clamp recordings of evoked release from red $e$ (left) and $S N A P-25^{\text {ts }}$ (right) 3rd instar larvae neuromuscular junction at $22^{\circ} \mathrm{C}$. Representative traces are the average of 20 individual stimuli. Scale bars: $10 \mathrm{nA}$ (vertical) and $10 \mathrm{~ms}$ (horizontal). B Linear and log-log plot of synaptic current amplitude versus $\mathrm{Ca}^{2+}$ concentration at $22^{\circ} \mathrm{C} . S N A P-25^{\text {ts }}$ showed enhanced neurotransmitter release. Twenty stimuli, delivered at $1 \mathrm{~Hz}$, were recorded from each cell, and each data point represents the average obtained from 5-9 cells. Error bars, where visible, are \pm SEM. Closed symbols $=$ red $e$; open symbols $=S N A P-25^{\text {ts }}$. C Quantification of evoked release from the indicated genotypes at $22^{\circ} \mathrm{C}$ in $0.8 \mathrm{mM} \mathrm{Ca}{ }^{2+}$. The data are the average results obtained from 6-9 cells. Reproduced from Rao et al. [35] with permission.

temperatures. This point mutation is a glycine50-to-glutamine substitution near the N-terminus. With this mutation, the SNARE complex becomes unstable at high temperatures [35].

\section{Nerve-Evoked Synaptic Currents}

Unexpectedly, at a permissive temperature, $22^{\circ} \mathrm{C}$, the amplitude of nerve-evoked synaptic currents in $S N A P$ $25^{\text {ts }}$ larvae was about 2 times larger than that in the control in the presence of $0.8 \mathrm{mM}$ external Ca ${ }^{2+}$ (fig. 4A, C). The plot of the nerve-evoked current amplitude versus the external $\mathrm{Ca}^{2+}$ concentration apparently shifted to the left in the mutant relative to the control, suggesting that the affinity of $\mathrm{Ca}^{2+}$ increased. In the double-logarithmic plot, the slope, which represents the apparent $\mathrm{Ca}^{2+}$ cooperativity, N, was about 3 , which is not different from the control (fig. 4B).

In contrast, at $37^{\circ} \mathrm{C}$, the nerve-evoked synaptic potential was reduced by $60 \%$ in amplitude compared with that

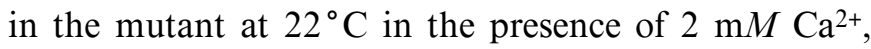
which was similar to that in the control at permissive temperatures. This reduction of synaptic currents in the mutant could be overcome by higher concentrations of $\mathrm{Ca}^{2+}$, as was found in cultured rat neurons after treatment with botulinum A [36], which is known to cleave SNAP-25 specifically [37]. What is intriguing is that this mutation affects a completely different site of the SNAP-25 molecule from botulinum A toxin (see below). Unfortunately, the relationship between external $\mathrm{Ca}^{2+}$ and the amplitude of evoked synaptic currents at $37^{\circ} \mathrm{C}$ was not studied.

\section{Minis}

The mini frequency was 6 times higher in 0 or $1 \mathrm{mM}$ external $\mathrm{Ca}^{2+}$ at $22^{\circ} \mathrm{C}$ in $S N A P-25^{\text {ts }}$ than in the control. The amplitude of minis was not different from that in the control, nor was the number of presynaptic boutons. These findings suggest that the probability of vesicle release at each presynaptic release site for spontaneous vesicle fusion is higher in the mutant at $22^{\circ} \mathrm{C}$. The mini frequency was not different from that in the control at $37^{\circ} \mathrm{C}$, in spite of the decrease in the amplitude of nerveevoked synaptic currents [35].

\section{Effects of Knockout of the SNAP-25 Gene in Mice}

In mice in which the SNAP-25 gene was knocked out, structures of the neuromuscular synapse were formed normally. In neuronal cultures obtained from these mutant embryos, evoked synaptic transmission was completely abolished. Again, minis remained, but the frequency varied over a wider range than in the control. The amplitude of minis was twice as large as that in the control, which is most likely to be due to reduced development of cholinesterase at the synaptic cleft in the mutant [38]. It is not known whether the lack of nerve-evoked synaptic currents in these mice can be overcome with higher concen- 
trations of external $\mathrm{Ca}^{2+}$, as was found in rats treated with botulinum A toxin (see below).

\section{Effects of Botulinum A Toxin in Rats}

Botulinum A toxin cleaves SNAP-25 at a site close to the carboxyl terminal, only 9 amino acids away from the end [37], and completely blocks action potential-induced release of transmitters in cultured rat hippocampal neurons. Interestingly, this effect of the toxin is partially overcome by increasing external $\mathrm{Ca}^{2+}$ concentrations. The relation between the external $\mathrm{Ca}^{2+}$ concentration and the amplitude of evoked synaptic currents shifted to the right after toxin treatment, but the apparent $\mathrm{Ca}^{2+}$ cooperativity, $N$, remained the same, indicating a lower sensitivity to $\mathrm{Ca}^{2+}$ in toxin-treated synapses [36]. This shift is opposite to what has been found in a Drosophila mutant, SNAP$25^{\text {ts }}$, at room temperature [35]. In both cases, the structural change in SNAP-25 is supposedly small, but the effect is prominent. Botulinum A toxin cleaves off only 9 amino acids at the $\mathrm{C}$ terminus, and $S N A P-25^{\text {ts }}$ has a mutation of only one amino acid, which exerts virtually no effect on Drosophila SNARE formation at room temperature [35]. Since SNAP-25 does not have $\mathrm{Ca}^{2+}$ binding sites, it appears that SNAP-25 is closely linked to the $\mathrm{Ca}^{2+}$ sensor, probably Syt I.

Even after treatment with botulinum A toxin, minis remained, albeit with a reduced frequency. The mini frequency increased with ionomycin in the presence of external $\mathrm{Ca}^{2+}$, but the extent of the increase was much less than in the control [36]. Assuming that ionomycin works similarly before and after botulinum A toxin treatment, this result indicates that the $\mathrm{Ca}^{2+}$ sensitivity for minis is also reduced after cleavage of SNAP-25.

Finally, it is interesting to note that after treatment with botulinum A toxin, the hypertonicity response induced by $100 \mathrm{~m} M$ sucrose is abolished in cultured rat hippocampal neurons [36], suggesting that an intact SNARE complex is required for the hypertonicity response.

\section{Interaction between SNAP-25 and $\mathrm{Ca}^{2+}$ Channels in HEK Cells}

When SNAP-25 was coexpressed with rat isoform (rbA) of a $\mathrm{Ca}^{2+}$ channel subunit, $\alpha 1 \mathrm{~A}$, in HEK293 cells, the steady-state inactivation curve for $\mathrm{Ca}^{2+}$ inward currents was shifted $9.7 \mathrm{mV}$ in the negative direction along the voltage axis compared with that in cells in which only rbA was expressed. When the whole SNARE complex was formed, together with Syx 1A and n-Syb, $\mathrm{Ca}^{2+}$ currents were no longer affected. Thus, this interaction between SNAP-25 and $\mathrm{Ca}^{2+}$ channels seems prevent $\mathrm{Ca}^{2+}$ influx when the SNARE complex formation is not ready [39]. In this expression system, the steady-state inactivation curve in the control had a half-inactivation point at $-20 \mathrm{mV}$ (that is, half of the $\mathrm{Ca}^{2+}$ channels are inactivated at the membrane potential of $-20 \mathrm{mV}$, and more channels will be inactivated at more depolarized potentials). In the resting state, in which the membrane potential of the presynaptic terminal is most likely to be more negative than $-60 \mathrm{mV}$ and all $\mathrm{Ca}^{2+}$ channels are in a noninactivated state, this shift of the inactivation curve would not affect the $\mathrm{Ca}^{2+}$ inward current. Only when the membrane potential becomes less negative than $-40 \mathrm{mV}$ will this negative shift of the inactivation curve induced by SNAP-25 become effective. Some $\mathrm{Ca}^{2+}$ channels will enter the inactivated state in the presence of SNAP-25. Accordingly, only when short depolarizing pulses at a very high frequency $(250 \mathrm{~Hz})$ were delivered did the inward current further decline in the presence of SNAP25 . The significance of this effect in situ has to be further investigated.

\section{Syntaxin 1A}

Synaptic transmission in $s y x^{\text {null }}$ embryos was studied in two null alleles, $s y x^{\Delta 229}$ [40] and $s y x^{\mathrm{L} 371}$ [41], and the results are slightly different. The difference seems to originate from the experimental conditions. Synaptic transmission in $s y x^{\Delta 229}$ embryos has been studied at abdominal muscle No. 6 in embryos 22-24 h after fertilization [18]. Morphologically, the number of boutons was reduced by $30-50 \%$ in mutant embryos. In electron microscopy (EM), synaptic vesicles were clustered in the vicinity of the release site (T-bar), and some of them appeared to be morphologically docked. Thus, it was concluded that Syx is not required for docking, contrary to the original proposal for a role of Syx in docking [42]. The only difference that was noted in $s y x^{\Delta 229}$ embryos in EM was an unusual abundance of enlarged vesicles besides normal ones in the presynaptic terminal. The significance of this finding is not known.

\section{Nerve-Evoked Synaptic Currents}

No nerve-evoked synaptic currents were observed in $s y x^{\Delta 229}$ embryos. However, with iontophoretic application of glutamate, robust inward currents, as large as those in controls, were evoked, suggesting that glutamate receptors are clustered at the junction as in wild-type embryos [18]. Later, Featherstone et al. [43] stained receptor clusters using an antibody against a glutamate receptor sub- 
unit and found receptor clusters 'indistinguishable' from those in wild-type embryos.

In $s y x^{\mathrm{L} 371}$ embryos, no nerve-evoked synaptic currents were detected, in accord with the result in $s y x^{\Delta 229}$. However, after puff application of glutamate at the junction with a pipette containing $1 \mathrm{~m} M$ glutamate, only small inward currents were evoked, suggesting that receptors are minimally clustered in the postsynaptic membrane. Corroborating this electrophysiological finding, receptor clusters at the synaptic area were hardly found in $s y x^{\mathrm{L} 371}$ embryos 18-21 h after fertilization [19]. Thus, findings in these two $s y x^{\text {null }}$ alleles are in disagreement.

\section{Minis}

In $s y x^{\Delta 229}$ embryos, minis in $\mathrm{Ca}^{2+}$-free saline were observed, although rarely (less than $0.3 / \mathrm{min}$ ) [18]. Contrary to this finding in $s y x^{\Delta 229}$, no minis were observed in syx ${ }^{\mathrm{L} 371}$ embryos around $21 \mathrm{~h}$ after fertilization [19].

One explanation for this discrepancy in findings between $s y x^{\mathrm{L} 371}$ and $s y x^{\Delta 229}$ is as follows: although both alleles are null, maternally deposited mRNA and protein (the maternal factor) are present at early stages [41]. There could be a subtle difference in the amount and/or the timing of the disappearance of the maternal factor between these two alleles. Even in $s y x^{\mathrm{L} 371}$, small and infrequent minis were detected at earlier stages $(16-17 \mathrm{~h}$ after fertilization), but not later [Hou, D., Kidokoro, Y., unpubl. observation]. It takes a few hours for receptors to form clusters after the appearance of minis during development. By the time receptor clusters are formed, no release of transmitter occurs as the maternal factor runs out. Thus, some receptor clustering may occur in $s y x^{\mathrm{L} 371} \mathrm{em}-$ bryos at late stages, but those receptor clusters will dissipate due to lack of a continuous supply of the clustering agent. In fact, glutamate-induced currents in $s y x^{\mathrm{L} 371} \mathrm{em}-$ bryos were distinctly smaller in amplitude than in wildtype embryos $[19,44]$.

\section{Hypertonicity Response}

Application of hypertonic sucrose solutions (450 or 600 mosm) induced quantal synaptic events in $s y x^{\Delta 229}$ embryos, although the frequency of events was low compared with those in wild-type embryos [18]. In contrast with this report, Aravamudan et al. [21] observed no response to a very hypertonic solution (1,175 mosm). An explanation was offered as follows [21]: in the previous report [18], nonspecific currents induced by puff application of a hypertonic solution, i.e. slow inward currents, were mistakenly considered to be the receptor-mediated hypertonicity response. Therefore, Aravamudan et al.
[21] concluded that there is no hypertonicity response in sy $x^{\Delta 229}$ embryos. However, in the original figure, quantal synaptic events were clearly displayed during the hypertonicity response [18], which cannot be accounted for by this explanation. Thus, this discrepancy still remains unexplained.

The hypertonicity response was not observed in syx ${ }^{\mathrm{L} 371}$ embryos [Suzuki, K., Kidokoro, Y., unpubl. observation].

\section{Syntaxin H3 Domain}

More detailed structure-function analyses have been conducted by generating Drosophila transformants which carry altered $s y x$ genes in the background of $s y x^{\text {null }}$ $\left(s y x^{\Delta 229}\right)$. The role of the H3 domain is of particular interest, because with this domain, Syx 1A binds to multiple synaptic proteins, e.g. Syt I, SNAP-25, $\mathrm{Ca}^{2+}$ channels and others [45] (fig. 5, 'wt syx'). Alterations of this domain profoundly affected synaptic transmission $[46,47]$. The $\mathrm{H} 3$ domain was subdivided into $s y x \mathrm{H} 3-\mathrm{N}$ and $s y x \mathrm{H} 3-\mathrm{C}$ (fig. 5). Elimination of $s y x \mathrm{H} 3-\mathrm{N}$ inhibited SNARE complex formation and synaptic transmission was abolished. These transformant embryos did not respond to nerve stimulation. No minis were detected (fig. 5, 'syxH3-N').

On the other hand, when syx $\mathrm{H} 3-\mathrm{C}$ was eliminated, altered Syx 1A did not bind to Syt I nor to synprint peptides $\left(\mathrm{Ca}^{2+}\right.$ effector domain; fig. 5, 'syxH3-C'). In this transformant embryo, nerve-evoked synaptic currents were dramatically reduced. In contrast, the frequency of minis increased almost two-fold in this transformant. Since these phenotypes seemed to be similar to those in $s y t^{\text {null }}$ mutant embryos [48], this effect was interpreted to be the result of dissociation from Syt I, rather than from N-type $\mathrm{Ca}^{2+}$ channels [47]. Characteristics of synaptic transmission in $s y t^{\mathrm{AD} 4}\left(s y t^{\text {null }}\right)$ and $s y x \mathrm{H} 3-\mathrm{C}$ are qualitatively similar, but quantitatively, impairment of nerveevoked synaptic transmission is more severe in $s y t^{\mathrm{AD} 4}$ than in $s y x^{\mathrm{H} 3-\mathrm{C}}$. Furthermore, the four-fold elevation of mini frequency in $s y t^{\mathrm{AD} 4}$ embryos reported by Broadie et al. [48] was not confirmed by Kidokoro and Suzuki [20] . Therefore, this interpretation should be considered to be tentative.

Point mutations in the syx $\mathrm{H} 3-\mathrm{N}$ domain yielded an interesting phenotype. An I212A substitution (isoleucine to alanine, this mutation is named $s y x^{2}$, fig. 5) eliminates binding to synprint, and another I236A substitution specifically abolishes binding to rop (sy $\left.x^{3}\right)$ [49]. Remarkably, both of these substitutions enhanced nerve-evoked synaptic transmission. Therefore, both interactions were interpreted to be negatively regulatory. Similarly, the interac- 
Fig. 5. Effects of mutations in the $\mathrm{H} 3$ domain of Drosophila Syx 1A: binding properties and synaptic transmission. Binding was assayed for SNAP-25, rop [49], Syt I and synprint. SNARE core formation was assayed after incubating the GST fusion proteins with both Syb and SNAP-25. Four coiled-coil domains are named $\mathrm{H} 1$ (HA), H2 (HB), $\mathrm{HC}$ and $\mathrm{H} 3$. Constructed with the data published by Wu et al. [46] and Fergestad et al. [47].

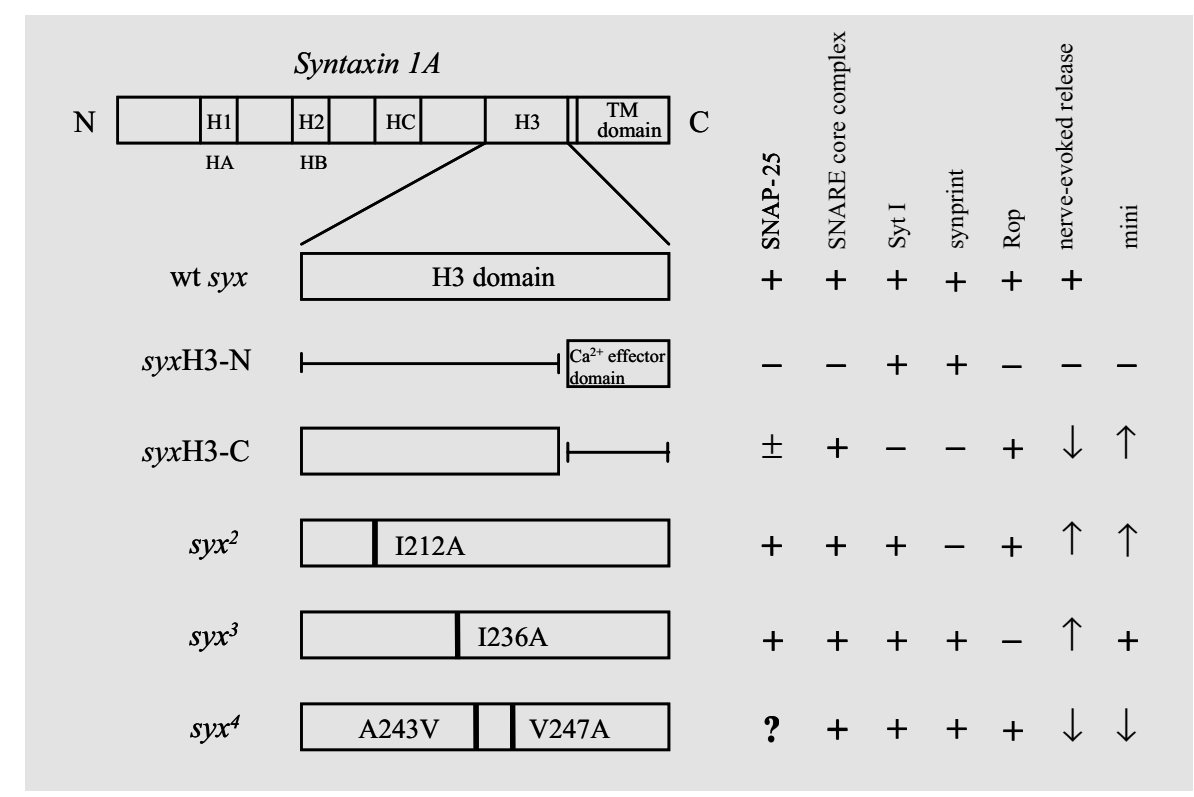

tion between Syx 1A and N-type $\mathrm{Ca}^{2+}$ channels was considered to negatively regulate synaptic transmission in the Xenopus oocyte expression system [50], although the binding site for this interaction is different from the synprint site [45].

A two-point mutation (A240V and V244A, called $s y x^{4}$, fig. 5) was generated in the $5 y x \mathrm{H} 3-\mathrm{N}$ domain. These two amino acids are considered to be a site other than synprint and involved in the negatively regulatory interaction with $\mathrm{N}$-type $\mathrm{Ca}^{2+}$ channels [45]. This mutation is supposed to disrupt an interaction between Syx 1A and N-type $\mathrm{Ca}^{2+}$ channels, while SNARE complex formation stays untouched. If this interaction were negatively regulatory, as was found in the oocyte expression system [45, 50], larger nerve-evoked synaptic currents would be expected. Nerve-evoked synaptic currents were, however, severely inhibited in $s y x^{4}$ embryos. The frequency of minis was also reduced to about a half of that of the control. Thus, the phenotype of $s y x^{4}$ is completely different from that of sy $x^{2}$, which also disrupts the interaction between Syx 1A and $\mathrm{N}$-type $\mathrm{Ca}^{2+}$ channels. From this phenotype alone, one could reach the conclusion that the interaction between Syx $1 \mathrm{~A}$ and $\mathrm{N}$-type $\mathrm{Ca}^{2+}$ channels is positively regulatory, but other authors have suggested that the same residues required for Syx-mediated $\mathrm{Ca}^{2+}$ channel inhibition are required for the generation of fusion-competent vesicles in a neuronal-specific mechanism acting at synapses [47]. Whether or not this interpretation is correct remains to be seen.

SNARE Proteins and Synaptotagmin I in Synaptic Transmission

\section{Interaction of Syx $1 A$ with $\mathrm{N}$-Type $\mathrm{Ca}^{2+}$ Channels}

\section{Studied in Other Preparations}

Two sets of opposing effects have been reported when the interaction between Syx $1 \mathrm{~A}$ and the N-type $\mathrm{Ca}^{2+}$ channel was interrupted. Mochida et al. [25] investigated this by injecting synprint peptides into the presynaptic neuron in cultures of rat superior cervical ganglion neurons. Synprint peptides contain the same amino acid sequences as a syntaxin interaction (synprint) site in the large cytosolic loop between repeats II and III in the $\alpha 1 \mathrm{~B}$ subunit of the $\mathrm{N}$-type $\mathrm{Ca}^{2+}$ channel and inhibit interaction between Syx $1 \mathrm{~A}$ and the N-type $\mathrm{Ca}^{2+}$ channel. Injection of synprint peptides inhibited nerve-evoked synaptic potentials but did not affect voltage-activated $\mathrm{Ca}^{2+}$ currents recorded at the cell body. Furthermore, asynchronous transmitter release after repetitive stimulation of the presynaptic neuron increased after synprint injection. These results were interpreted as indicating that the synprint peptide bound to Syx $1 \mathrm{~A}$ at the site where the $\mathrm{N}$-type $\mathrm{Ca}^{2+}$ channel normally binds and prevented interaction between Syx 1A and the $\mathrm{Ca}^{2+}$ channel. Dissociation of Syx $1 \mathrm{~A}$ and the Ntype $\mathrm{Ca}^{2+}$ channel resulted in looser coupling between $\mathrm{Ca}^{2+}$ influx and vesicle fusion.

This view was supported by Rettig et al. [51] in their study of Xenopus nerve-muscle cultures. They injected peptides containing the synprint sequence into early blastomeres and examined synaptic transmission between motoneurons and muscle cells in culture. In this system, the amplitude of synaptic currents is inherently variable, 
and it is difficult to compare directly between preparations with the synprint peptide injected and not injected. However, when the external saline containing $1.8 \mathrm{mM}$ $\mathrm{Ca}^{2+}$ was switched to saline containing $10 \mathrm{mM} \mathrm{Ca}^{2+}$, they observed that the amplitude of synaptic currents increased approximately 1.25 -fold in the control, whereas it increased approximately 2.5 -fold in injected cells. This was interpreted as indicating that the amplitude at $1.8 \mathrm{mM} \mathrm{Ca}{ }^{2+}$ was inhibited by the peptide injection. This modulation of synaptic current amplitudes did not occur when the corresponding peptides from L-type $\mathrm{Ca}^{2+}$ channels were injected. Rettig et al. [51] also measured $\mathrm{Ca}^{2+}$ influx at the presynaptic terminal with a $\mathrm{Ca}^{2+}$ indicator, fura-2, and found no difference between injected and uninjected preparations. Thus, these results were interpreted as showing that $\mathrm{Ca}^{2+}$ channels were working normally, but the close contact between Syx 1A and N-type $\mathrm{Ca}^{2+}$ channels was interrupted.

Later, the synprint peptide was also found to bind to the $\mathrm{C}_{2} \mathrm{~B}$ domain of Syt I [52]. It is thus not clear whether the effect of injected synprint peptides is mediated through binding to Syx 1A or to Syt I. In either case, nerve-evoked synaptic currents will be reduced.

In contrast to this positively regulatory interaction between Syx 1A and the N-type $\mathrm{Ca}^{2+}$ channel, Bezprozvanny et al. [45] found that the interaction between Syx $1 \mathrm{~A}$ and $\mathrm{N}$-type or Q-type $\mathrm{Ca}^{2+}$ channels is negatively regulatory. In the Xenopus oocyte expression system, they expressed Syx 1A and $\mathrm{N}$-type $\mathrm{Ca}^{2+}$ channels and found that the relation between the amplitude of inward $\mathrm{Ca}^{2+}$ currents and the holding potential shifted by approximately $20 \mathrm{mV}$ in the negative direction in the presence of Syx 1A compared with its absence. In this case, the halfinactivation point was at around $-84 \mathrm{mV}$ when $\mathrm{Ca}^{2+}$ channels were expressed alone. Thus, at a potential of around $-80 \mathrm{mV}$, in the presynaptic terminal, about half of $\mathrm{Ca}^{2+}$ channels will be inactivated, and a shift of $20 \mathrm{mV}$ in the negative direction in the presence of Syx 1A will further increase the proportion of channels in the inactivated state. This shift was observed with Q-type $\mathrm{Ca}^{2+}$ channels but not with L-type $\mathrm{Ca}^{2+}$ channels. Furthermore, when the H3 domain was deleted from Syx 1A, the shift was not observed. This work was further followed by Bezprozvanny et al. [45], and the site of interaction between Syx 1A and N-type $\mathrm{Ca}^{2+}$ channels for this modulation was determined. Ala-240 and Val-244 were found to be critically involved in this modulation. Interestingly, this site is not the synprint binding site. Therefore, the interaction between Syx 1A and $\mathrm{N}$-type $\mathrm{Ca}^{2+}$ channels occurs at least at two sites, and these two sites have opposite effects.

\section{Synaptotagmin I}

A synaptic vesicular protein, Syt I has two $\mathrm{Ca}^{2+}$ binding domains, $\mathrm{C}_{2} \mathrm{~A}$ and $\mathrm{C}_{2} \mathrm{~B}$, and is hypothesized to be a major $\mathrm{Ca}^{2+}$ sensor for fast synchronous synaptic transmission following nerve stimulation [53]. The Drosophila neuromuscular synapse is suitable to test this hypothesis as a variety of alleles of syt $I$ mutants are available.

\section{Nerve-Evoked Synaptic Currents}

Larvae of hypomorphic alleles survive to 3rd instars. In those larvae, the amplitude of nerve-evoked synaptic potentials was dramatically reduced. The maximum amplitude at a high concentration of external $\mathrm{Ca}^{2+}(6 \mathrm{mM})$ was about one quarter of that of wild-type larvae. The $\mathrm{Ca}^{2+}$ dependency of quantal contents was less steep in mutant larvae than in wild-type larvae, and the apparent cooperativity, $\mathrm{N}$, was found to be approximately 1.5 in the mutants, which was smaller than that in the control (approximately 3.5) [54]. These results are in accord with the idea that Syt I is a $\mathrm{Ca}^{2+}$ sensor for vesicle fusion.

syt I-null mutants $\left(s y t^{\mathrm{AD} 4}\right)$ are embryonically lethal but survive to the late embryonic stage, and synaptic transmission at the neuromuscular synapse has been studied. In those embryos, nerve-evoked synaptic transmission was severely impaired but not abolished. The amplitude of synaptic current at $1.8 \mathrm{mM}$ external $\mathrm{Ca}^{2+}$ in the mutant embryos was about one tenth of that in wild-type embryos. When the external $\mathrm{Ca}^{2+}$ concentration was decreased, the amplitude also diminished in $s y t^{\mathrm{AD} 4} \mathrm{em}-$ bryos, indicating that $\left[\mathrm{Ca}^{2+}\right]_{i}$ is sensed by another $\mathrm{Ca}^{2+}$ sensor. In the double-logarithmic plot between the quantal content of synaptic currents and the external $\mathrm{Ca}^{2+}$ concentration, the slope, i.e. the apparent $\mathrm{Ca}^{2+}$ cooperativity, $\mathrm{N}$, was 1.7 for the mutant and 1.8 for wild-type embryos within the low concentration range $(0.02$ and $0.4 \mathrm{mM})$. The $\mathrm{Ca}^{2+}$ sensitivity remained similar in the mutant [48]. Thus, smaller synaptic currents in $s y t^{\mathrm{AD} 4}$ embryos at a given $\mathrm{Ca}^{2+}$ concentration have to be explained by a smaller maximal response in saturating $\mathrm{Ca}^{2+}$ concentrations. These findings are unexpected, because if Syt I were a major $\mathrm{Ca}^{2+}$ sensor, the apparent $\mathrm{Ca}^{2+}$ cooperativity should change in the absence of Syt I, and the remaining $\mathrm{Ca}^{2+}$ sensor is likely to have a different $\mathrm{Ca}^{2+}$ sensitivity $\left(\mathrm{K}_{\mathrm{d}}\right)$. Further, the apparent $\mathrm{Ca}^{2+}$ cooperativity of 1.8 in wild-type embryos is small, which the authors attributed to characteristics of immature synapses. However, a larger N, close to 4, has been reported for Drosophila embryos [30]. Thus, these findings in $s y t^{\mathrm{AD} 4}$ and wild-type embryos are rather incoherent. 


\section{Minis}

Unexpectedly, in 3rd instar larvae of hypomorphic alleles, the mini frequency was 4 times higher in syt mutants than in wild-type larvae [54-56]. This finding led to a speculation that Syt I is a negative regulator of vesicle fusion as well as being a $\mathrm{Ca}^{2+}$ sensor [57]. Syt I might prevent vesicles from premature fusion, so that vesicles are ready for synchronized fusion by a fast rise in $\left[\mathrm{Ca}^{2+}\right]_{i}$ during an action potential. However, as described below, the mini frequency in $s y t^{\text {null }}$ embryos was found to be similar to that in wild-type embryos. Since these 3 rd instar larvae had ample time during development to adjust to defective Syt I, the observed high frequency of minis could be the result of adaptive modulation during the developmental process.

The frequency of minis was reported to be 4 times higher in syt $t^{\mathrm{AD} 4}$ embryos than in wild-type embryos [48]. More recently, neuromuscular synaptic transmission in $s y t^{\mathrm{AD} 4}$ embryos was reexamined [20], and the dramatic decrease of nerve-evoked synaptic currents in mutant embryos was confirmed. However, the mini frequency in the mutant embryos was not different from that in a control under various external $\mathrm{Ca}^{2+}$ concentrations. This result is in accord with the report regarding cultured neurons from knockout mice in which syt I was deleted [58]. Thus, it is likely that the mini frequency in $s y t^{\mathrm{AD} 4}$ embryos is not different from that in wild-type embryos. The mini frequency in $s y t^{\mathrm{AD} 4}$ embryos was higher in external solutions containing higher $\mathrm{Ca}^{2+}$ concentrations, indicating that another $\mathrm{Ca}^{2+}$ sensor for minis remains [20].

\section{Roles of Two $\mathrm{Ca}^{2+}$ Binding Domains in Syt I}

Syt I has two $\mathrm{Ca}^{2+}$ binding domains, $\mathrm{C}_{2} \mathrm{~A}$ and $\mathrm{C}_{2} \mathrm{~B}$ [59]. The roles of these domains can be explored by using $s y t$ alleles that have various defects in these domains. Among $s y t$ alleles, $s y t^{\mathrm{AD} 1}$ does not have $\mathrm{C}_{2} \mathrm{~B}$ due to insertion of a premature stop codon, while $s y t^{\mathrm{AD} 3}$ has one amino acid substitution in $\mathrm{C}_{2} \mathrm{~B}$ (fig. 6) [56]. Mutant Syt I proteins in these two alleles were made and targeted to synapses [60]. Thus, these two alleles provide an excellent opportunity to further examine the function of Syt I. Desai et al. [59] found that in $s y t^{\mathrm{AD} 1}$ mutants, synaptic transmission did not occur at low $\mathrm{Ca}^{2+}(0.4 \mathrm{mM})$ and was marginally rescued at a high $\mathrm{Ca}^{2+}$ concentration $(6 \mathrm{mM})$. In EM, vesicles were partly depleted from presynaptic nerve terminals at photoreceptor synapses after prolonged light stimulation. In contrast, in $s y t^{\mathrm{AD} 3}$ mutants, synaptic vesicles were still observed in the terminal under the same conditions. In the biochemical assay, the clathrin adaptor protein, AP-2, did not bind to AD1 Syt, whereas it does bind to AD3.
Thus, they concluded that the $\mathrm{C}_{2} \mathrm{~B}$ domain is required for endocytosis. (The role of Syt I in endocytosis will be discussed below.) They stated that since there are no synaptic vesicles in $s y t^{\mathrm{AD} 1}$ in the presynaptic nerve terminal, the role of $\mathrm{C}_{2} \mathrm{~B}$ in exocytosis cannot be studied [59]. However, in a $s y t$-null allele, $s y t^{\mathrm{AD} 4}$, in which vesicles were found in EM [48, 61], minis were readily observed [48]. The diminished number of synaptic vesicles in the terminal in $s y t^{\mathrm{AD} 1}$ could be due to intensive stimulation before fixation [59]. There could be a second endocytotic pathway that does not require AP-2. Alternatively, in $s y t^{\mathrm{AD} 4}$, Syt IV might substitute Syt I for endocytosis. Syt IV is known to bind to AP-2 as effectively as Syt I [62].

The function of $\mathrm{C}_{2} \mathrm{~B}$ was further studied in $s y t^{\mathrm{AD} 3}$, in which asparagine substitutes tyrosine at position 364 . This site is highly conserved between Caenorhabditis elegans and humans. This substitution turned out to have a profound effect on nerve-evoked synaptic transmission at a low concentration of $\mathrm{Ca}^{2+}(0.4 \mathrm{mM})$, but synaptic transmission was partially rescued at $6 \mathrm{~m} M \mathrm{Ca}^{2+}$. The relation between the amplitude of nerve-evoked synaptic potentials and external $\mathrm{Ca}^{2+}$ concentration in 3 rd instar $s y t^{\mathrm{AD} 3}$ larvae (viable when paired with other $s y t$ alleles) was shifted to the right without changing the apparent $\mathrm{Ca}^{2+}$ cooperativity (3.6) [54]. These results suggest that the AD3 mutation decreased the sensitivity of Syt I to $\mathrm{Ca}^{2+}$.

The $\mathrm{Ca}^{2+}$-induced conformational change in $\mathrm{C}_{2} \mathrm{~B}$ was impaired by the AD3 mutation, and oligomerization of Syt I was reduced to approximately $40 \%$ of that of the wild type. Since this $\mathrm{Ca}^{2+}$-dependent oligomerization is conserved between invertebrates and mammals, this could be an important process for the function of Syt I [59]. Thus, the defect in synaptic transmission in $s y t^{\mathrm{AD} 3}$ could be explained by the impaired oligomerization of Syt I.

\section{A Homolog of Syt I, Syt IV}

Syt IV is enriched in Drosophila synaptic vesicles. $\mathrm{Ca}^{2+}$ binding sites in the $\mathrm{C}_{2} \mathrm{~B}$ domain are conserved in Syt IV, but because of a substitution of aspartate with serine in the third $\mathrm{Ca}^{2+}$ binding site in the $\mathrm{C}_{2} \mathrm{~A}$ domain, the ability to bind phospholipids in a $\mathrm{Ca}^{2+}$-dependent manner is impaired in Syt IV. Syt IV interacts with the clathrin adapter, AP-2, the synprint domain of N-type $\mathrm{Ca}^{2+}$ channels and Syx. When Syt IV was overexpressed using UASsyt IV and elav-Gal4 transgenes, nerve-evoked synaptic transmission was decreased by $21 \%$ compared with controls. On the other hand, when Syt I was overexpressed, no change was observed. These results were interpreted as follows: when Syt IV is overexpressed, more hetero-oligo- 
A
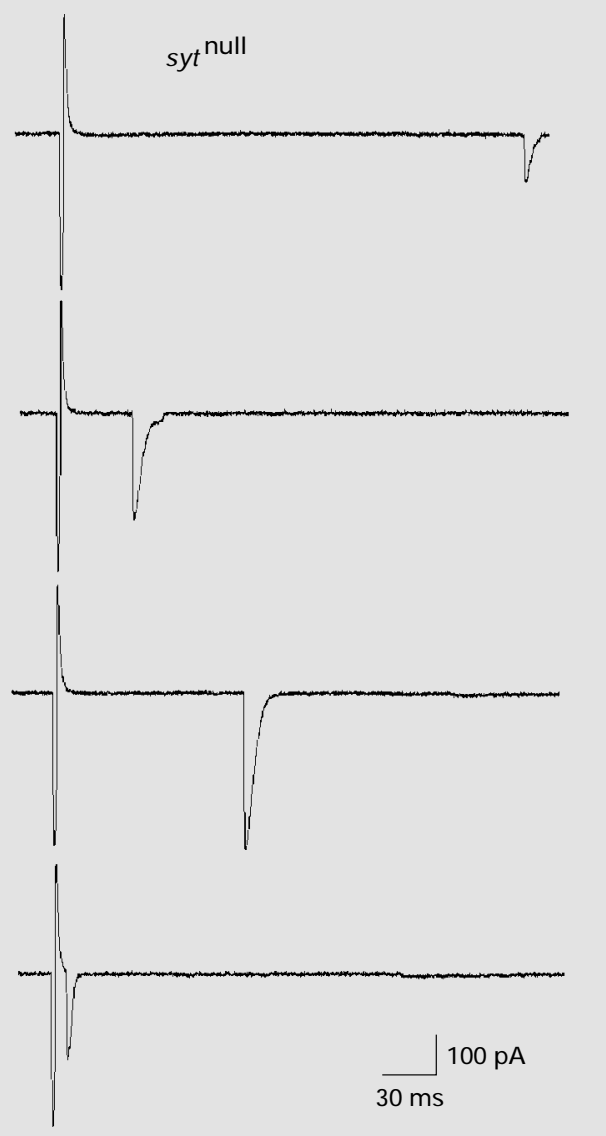

B

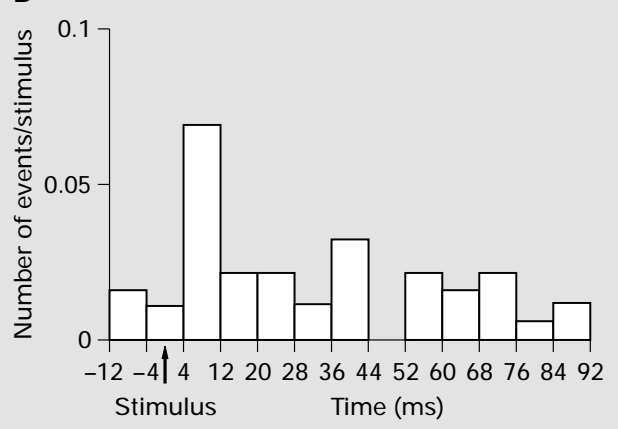

Control
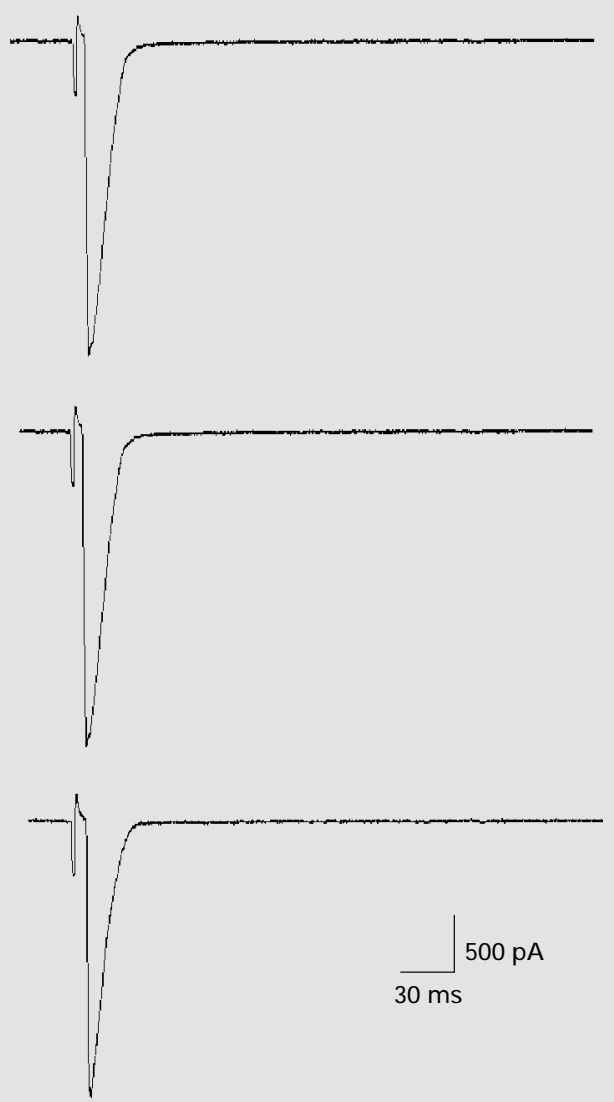

C

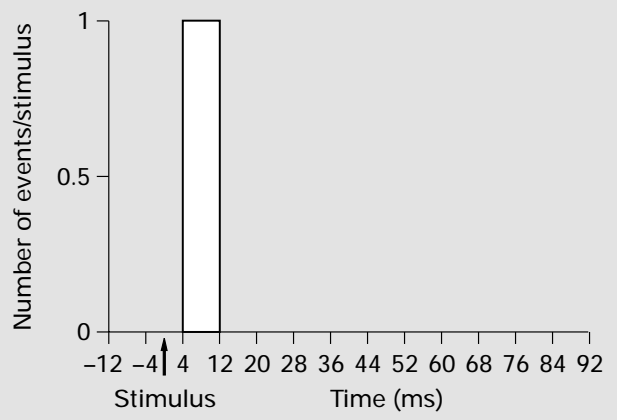

Fig. 6. Nerve-evoked synchronous and asynchronous synaptic currents in syt $t^{\text {null }}$ and control. In this experiment, a myosin heavy chain mutant, $M h c^{1}$ [82], was used as a control to avoid contraction during nerve stimulation. A double mutant, $s y t^{\mathrm{AD} 4} M h c^{1}$, was used to study the effect of $s y t^{\text {null }}$. A Sample traces of nerve-evoked synaptic currents from a $s y t^{\text {null }}$ embryo (left) and from control embryos (right). Recording was carried out in HL3 medium [83] containing $2 \mathrm{mM}$ $\mathrm{Ca}^{2+}$ for the mutant and $1.5 \mathrm{mMCa} \mathrm{Ca}^{2+}$ for the control. B A frequency histogram for synaptic events before and after nerve stimulation in a $s y t^{\text {null }}$ embryo. The number of events/stimulus is plotted against time. The total number of stimulations was 193 , at $0.3 \mathrm{~Hz}$. C A frequency histogram of synaptic currents after nerve stimulation in a control embryo. Spontaneous synaptic currents were rare. There were no failures among 24 stimuli at $0.3 \mathrm{~Hz}$ and all events were observed in the time window between 4 and $12 \mathrm{~ms}$ after stimulation. From Suzuki, K., Okamoto, N. and Kidokoro, Y. [unpubl. results]. 
mers will be formed between Syt I and IV, which have a poor ability to penetrate into phospholipids in a $\mathrm{Ca}^{2+}$ dependent manner, resulting in less effective coupling between $\mathrm{Ca}^{2+}$ influx and vesicle fusion. Since Syt IV is made in the wild type, some hetero-oligomers must be present in the presynaptic terminals in normal conditions, thus overexpression of Syt I should enhance the amplitude of synaptic currents, which was not adequately tested, since the amplitude of nerve-evoked synaptic potentials was already maximally large with $3 \mathrm{~m} M$ external $\mathrm{Ca}^{2+}$. Under this experimental condition, the effect of overexpression of Syt I might not be observed [62].

Interestingly, the mini frequency decreased in both Syt IV- and Syt I-overexpressing larvae. This result suggests that Syts are a negative regulator of spontaneous vesicle fusion. Overexpression of Syt IV did not affect recycling of synaptic vesicles [62]. Thus, the interaction between Syts and the vesicle fusion machinery for mini frequency modulation seems to occur without participation of phospholipids, because a major difference between Syt I and IV is in the $\mathrm{Ca}^{2+}$-dependent phospholipid binding.

Recently, this view of the role of Syt IV was challenged by Robinson et al. [63]. When Syt IV was expressed in the syt-null background $\left(s y t^{\mathrm{AD} 4}\right)$, synaptic transmission was rescued to the control level. Furthermore, when an aspartate residue in the $\mathrm{C}_{2} \mathrm{~A}$ domain was changed to asparagine (D2N), $\mathrm{Ca}^{2+}$-dependent binding of the $\mathrm{C}_{2} \mathrm{~A}$ domain with syntaxin and phospholipids was abolished. Next, the D2N transgene was expressed in larvae lacking Syt I and synaptic transmission was rescued. These results indicate that $\mathrm{Ca}^{2+}$ binding motifs in the $\mathrm{C}_{2} \mathrm{~A}$ domain are not essential for $\mathrm{Ca}^{2+}$ sensing. Furthermore, these results indicate that endogenous Syt IV did not substitute Syt I in $s y t^{\text {null }}$ larvae. Reinforcing this view further, Mackler et al. [64] substituted two aspartate residues in the $\mathrm{C}_{2} \mathrm{~B}$ domain with asparagine and found that synaptic transmission was heavily impaired. Thus, the $\mathrm{Ca}^{2+}$ binding motif in the $\mathrm{C}_{2} \mathrm{~B}$ domain must be required for $\mathrm{Ca}^{2+}$ sensing.

\section{Other Functions of Syt I}

Synaptotagmin may have functions other than sensing $\mathrm{Ca}^{2+}$. In EM, the overall number of synaptic vesicles was reduced in Drosophila syt $t^{\text {null }} 1$ st instars. In particular, the number of vesicles immediately adjacent to the presynaptic membrane, including docked vesicles, was reduced to $24 \%$ of that of control [61]. This finding suggests that transport of vesicles to release sites is compromised. Recycling of synaptic vesicles is defective in $s y t^{\text {null }}$ mutants of C. elegans, leading to depletion of synaptic vesicles at the synapse [65]. In addition, Syt I has been shown to bind to a clathrin adaptor, AP-2, which is essential for endocytosis [66]. Thus, recycling or transport of synaptic vesicles in the presynaptic terminal may also be impaired in $s y t^{\text {null }}$.

The C-terminus end of Syt I is well conserved across animal species. In the squid giant synapse, injection of a peptide which has the same sequence of 21 amino acids of the C-terminus reduced synaptic transmission. In these synapses, the number of docked vesicles was reduced, and the area immediately adjacent to the release site was devoid of vesicles in EM. Thus, the authors suggest that this end of Syt I serves for docking of synaptic vesicles [67]. However, since even in Drosophila embryos completely lacking Syt I, synaptic vesicles were docked at the release site and minis occurred [48], Syt I does not seem to be absolutely necessary for docking.

\section{Synaptic Transmission in Syt Mutant Embryos of Mice and $\mathrm{C}$. elegans}

In cultured mouse hippocampal neurons from mutant embryos lacking Syt I, the frequency of mSCs was unaffected, while the amplitude of nerve-evoked synaptic currents was very much diminished [58]. To further pinpoint the $\mathrm{Ca}^{2+}$ binding sites in Syt I, one-amino-acid substitutions in the $\mathrm{C}_{2} \mathrm{~A}$ domain were carried out. When an uncharged glutamine substituted a positively charged arginine (R233) close to a putative $\mathrm{Ca}^{2+}$ binding site in the $\mathrm{C}_{2} \mathrm{~A}$ domain (R233Q), the affinity of $\mathrm{Ca}^{2+}$ binding of the mutated $\mathrm{C}_{2} \mathrm{~A}$ domain decreased by a factor of 2 in the $\mathrm{Ca}^{2+}$-dependent phospholipid binding assay, while a similar substitution, i.e. lysine to glutamine (K236Q), in the nearby site did not. These mutated syt I genes were introduced into mice by homologous recombination, and the effects of these substitutions on synaptic transmission were tested in cultured neurons. With these substitutions, the overall conformation of Syt I did not change. The mean amplitude of nerve-evoked synaptic currents in R233Q mutant cells was about one half of that in K236Q or wild-type neurons. Neither the frequency nor amplitude of minis was different between R233Q and wild-type neurons. Furthermore, the hypertonicity response was not different among R233Q, K236Q and wild-type synapses. To eliminate the possibility that $\mathrm{Ca}^{2+}$ influx is impaired in R233Q neurons, voltage-gated $\mathrm{Ca}^{2+}$ channels were bypassed by a $\mathrm{Ca}^{2+}$ ionophore, calcimycin. The response was slower in R233Q neurons compared with wild-type neurons, suggesting that smaller nerve-evoked synaptic currents in R233Q neurons are not due to a lower influx of $\mathrm{Ca}^{2+}$ through voltage-gated $\mathrm{Ca}^{2+}$ channels, but rather that $\mathrm{Ca}^{2+}$ sensing is impaired in these mutant neurons. The 
amplitude of nerve-evoked synaptic currents was examined in various external $\mathrm{Ca}^{2+}$ concentrations. The curve in R233Q synapses shifted to the right $\left(\mathrm{K}_{\mathrm{d}}\right.$ of $3.7 \mathrm{~m} M$ in $\mathrm{R} 233 \mathrm{Q}$ versus $1.9 \mathrm{~m} M$ in wild-type neurons), and the saturating amplitude was $74 \%$ of that of wild-type neurons. The apparent $\mathrm{Ca}^{2+}$ cooperativity was not different. From these observations, the authors somehow reached the conclusion that the $\mathrm{C}_{2} \mathrm{~A}$ domain of Syt $\mathrm{I}$ is a $\mathrm{Ca}^{2+}$ sensor [68].

This conclusion contradicts that reached in studies of Drosophila mutants, in which ample evidence was presented to indicate that the $\mathrm{C}_{2} \mathrm{~B}$ domain is a $\mathrm{Ca}^{2+}$ sensor. However, the results in knockout mice do not exclude the possibility that the $\mathrm{C}_{2} \mathrm{~B}$ domain operates as a $\mathrm{Ca}^{2+}$ sensor. These two domains as a whole could serve as a $\mathrm{Ca}^{2+}$ sensor.

Mutants of $C$. elegans defective in the syt gene, snt-1, exhibit severe behavioral abnormalities in locomotion, feeding and defecation [69]. In those mutants, the number of synaptic vesicles was decreased, and release of acetylcholine was reduced at the neuromuscular synapse [65]. This effect could be due to a defect in endocytosis as Syt I interacts with AP-2 [66].

\section{Conclusions}

The Drosophila Neuromuscular Synapse as a Model for Studies of Synaptic Transmission

Many mutants of key proteins in the SNARE complex are embryonically lethal. The neuromuscular synapse, however, forms at relatively early stages of brain development in embryos and can be studied electrophysiologically using the patch-clamp technique. Alternatively, synapses of lethal mutants can be studied by growing neurons in culture. Synapses formed in culture, however, do not seem to be constrained with respect to the shape and extent of synaptic contact and have highly variable synaptic areas. In contrast, the synapse on a given muscle cell in a Drosophila embryo is stereotypic and relatively invariable in size [70], which makes the comparison of synapses among mutants easier. Hence, subtle changes in synaptic transmission in mutants can be detected.

It is obviously advantageous to use the Drosophila system for genetic manipulations, since all genes have been sequenced [71] and a large collection of synaptic mutants is readily available [72]. By directing expression of a protein of interest either in presynaptic neurons or muscle cells in the absence of the protein in the null mutant background (Gal4-UAS expression system) [73], we can easily determine its site of action for manifestation of a particular phenotype, either presynaptic or postsynaptic. By introducing a specifically modified transgene which does not change the overall conformation of the SNARE complex, it is possible to determine an active site of a protein for a specific task. Furthermore, a heat shock promoter can be used to overexpress a protein at a given time during development in a subset of neurons [74].

A temperature-sensitive paralytic mutant, shibire, was useful for the estimation of the number of vesicles in synaptic pools at the neuromuscular synapse of 3rd instar larvae. In this mutant, endocytosis ceases at non-permissive temperatures because of a defect in a protein, Dynamin, which is essential for this process, and synaptic terminals become completely depleted of synaptic vesicles after prolonged repetitive nerve stimulation. Thus, the total number of vesicles estimated by repetitively stimulating the nerve to complete cessation of synaptic currents was about 84,000 . Then, the size of each pool, the 'immediately releasable pool', 'readily releasable pool' and 'reserve pool', was determined by analyzing the time course of decline in the amplitude of synaptic currents during repetitive stimulation [75]. This is a unique case in which the sizes of all vesicle pools were determined in one synapse.

On the other hand, the Drosophila neuromuscular synapse might not be a good model for synapses in the central nervous system. So far, long-term changes in synaptic transmission have not been demonstrated at the neuromuscular synapse. However, this situation could be manipulated by artificially expressing necessary components in this synapse for long-term synaptic plasticity.

Overall, the Drosophila neuromuscular synapse offers an excellent model for investigation of the basic molecular mechanism of synaptic transmission.

\section{Distinct Mechanisms for Nerve-Evoked and \\ Spontaneous Synaptic Release}

One feature which stands out in the studies in Drosophila mutants $n$-sy $b^{\text {null }}$ and $s y t^{\text {null }}$ is that nerve-evoked synaptic currents are completely absent or severely reduced, while spontaneous release of vesicles remains in syt $I[20,48]$ and is only slightly altered in $n-s y b[16,17]$. Similarly, in temperature-sensitive SNAP-25 mutant larvae, the amplitude of nerve-evoked synaptic potentials was reduced at a non-permissive temperature, while the mini frequency did not change [35]. The SNARE complex seems to serve only for fast synchronous release, and spontaneous release (minis) might have a separate molecular machinery. Minis are often referred to as constitutive or $\mathrm{Ca}^{2+}$-independent fusion events, which is not quite 
Fig. 7. A schematic drawing of a tentative model that accommodates the findings in Drosophila mutant embryos. A detailed explanation is given in the text.

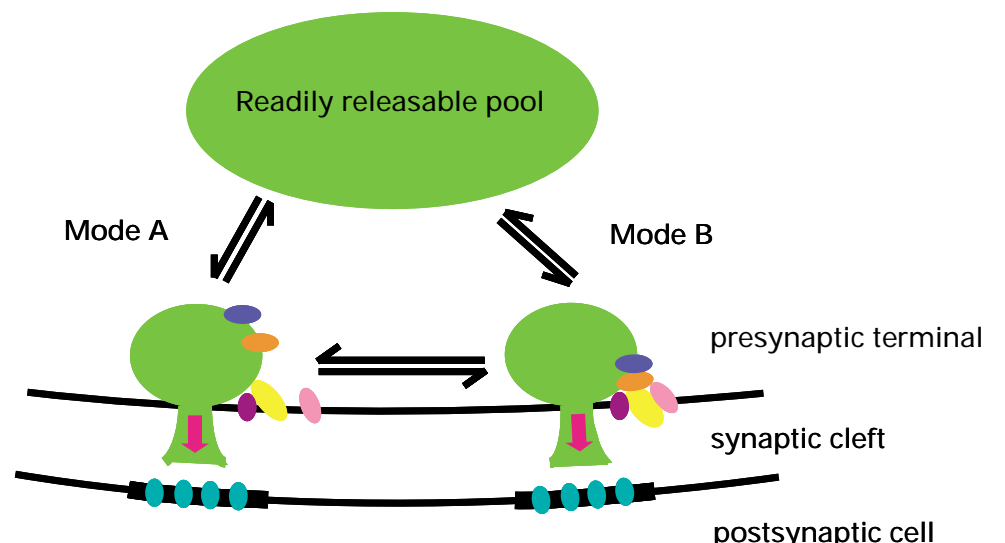

Synaptotagmin n-Synaptobrevin

n-Synaptobre

Syntaxin $1 \mathrm{~A}$

SNAP-25

glutamate receptors adequate in this case, because the major portion of minis, if not all, are $\mathrm{Ca}^{2+}$ dependent. In the absence of external $\mathrm{Ca}^{2+}$, the frequency of minis is usually very low, and even in this situation, $\left[\mathrm{Ca}^{2+}\right]_{\mathrm{i}}$ in the terminal might be contributing to spontaneous vesicle fusion. Although the function of minis is still unknown, one possibility was suggested by Saitoe et al. [44]. They found that when minis were absent during the formation of neuromuscular synapses, such as in $s y x^{\text {null }}$ embryos, postsynaptic receptor clustering did not occur, and they suggested that a signal molecule for receptor clustering, such as agrin at vertebrate neuromuscular synapses [76], is released from the presynaptic nerve terminal by the same mechanism as minis. Spontaneous release of trophic factors and transmitters might be necessary for the formation and maintenance of synapses.

In figure 7, a tentative model is depicted which accommodates the findings in various mutants in which a component of the SNARE complex or Syt I is defective or missing. In all of these mutant embryos, except $s y x^{\text {null, }}$, nerve-evoked synaptic currents are very much compromised, but minis remain. To accommodate this finding, in this model, there are two morphologically indistinguishable modes of vesicles, $\mathrm{A}$ and $\mathrm{B}$, and both of them are docked at release sites facing postsynaptic receptor clusters. Vesicles in the B mode have all the components of the SNARE complex and Syt I properly aligned and are ready to be released upon arrival of an action potential. These vesicles might constitute a pool called the immediately releasable pool' by Delgado et al. [75], the size of which is small, i.e. 230, in 3rd instar larvae, suggesting that about one half of the release sites are occupied by vesicles in this mode. These vesicles in the B mode may be protected from premature release at low $\mathrm{Ca}^{2+}$ concentrations.

In contrast, vesicles in the A mode require only Syx $1 \mathrm{~A}$ and probably nearby $\mathrm{Ca}^{2+}$ channels to be aligned, and $\mathrm{Ca}^{2+}$-dependent release of these vesicles produces minis, which can occur without n-Syb, SNAP-25 or Syt I. Vesicles in the A mode can also be released by nerve stimulation, but the efficacy of release is low. Immature synapses, such as those formed at the growth cone [77], could be constituted of vesicles entirely in this mode. Compared with vesicles in the $\mathrm{B}$ mode, those in the A mode can be released at relatively lower $\mathrm{Ca}^{2+}$ concentrations. These two modes of vesicles are in equilibrium with vesicles in the readily releasable pool [78] and are also interchangeable with each other in the wild type, in which all components of the SNARE complex and Syt I are available. High $\mathrm{K}^{+}$stimulation in the presence of external $\mathrm{Ca}^{2+}$ can release vesicles in either modes, but hypertonicity can release only vesicles in the B mode. During the hypertonicity response, vesicles in the B mode are replenished quickly by vesicles in the readily releasable pool and those in the 
A mode. This model seems to accommodate many of findings in mutant embryos. To substantiate this model, characteristics of vesicle release in each mode have to be further determined. For example, is A mode release more common in immature synapses? Does cAMP facilitate release in the B mode?

\section{Future Directions for Understanding Functions of the SNARE Complex}

Detailed studies of synaptic transmission after specific alteration of SNARE proteins are needed to understand the role of each protein. Although, in the past, it was essential to study the functions of key proteins in Drosophila null mutant embryos or in knockout mice, the consequences of those alterations are too extensive. In view of the delicate relation between the conformational state of proteins and function, it is difficult to analyze the consequence of large alterations. For example, when the whole SNARE complex does not form, it is impossible to pinpoint the role of a constituent protein, say SNAP-25, in synaptic transmission. The overall functional phenotype will be completely dictated by the lack of the SNARE complex. Alternatively, strategies to knock in altered genes in mice or to rescue a partial function by insertion of altered genes in the null mutant background of Drosophila are promising. Substitution of putative key amino acids one by one and careful examination of the consequences might be the only way to understand the function of each SNARE protein in synaptic transmission. It is likely that these proteins interact with each other at multiple sites. Each site should be distinguished by substitution of a key amino acid.
It is necessary to search for missing proteins that mediate selective docking of vesicles at the release site. Selective docking was at first thought to be one of the functions of the SNARE complex [79]. Subsequent studies in null mutant embryos, however, revealed that vesicles are docked in the absence of any of those key proteins [48]. Thus, there must be separate proteins that serve for docking. Munc-13 and RIM are supposed to be a part of active zone materials [80]. Synaptic transmission in Drosophila mutants lacking a homolog of unc-13 (dunc-13) was studied [21]. The phenotype was very similar to that of $n$-syb, suggesting that Drosophila unc-13 plays an important role in synaptic transmission. In EM, vesicles were found to be docked at the release site, suggesting that dunc-13 also operates downstream of docking.

Ultrastructural studies at the frog neuromuscular junction using electron microscopic tomography revealed elaborate structures at the presynaptic release site (active zone material). Vesicles are tethered by several 'ribs' to a 'beam' in the center forming two parallel rows. Each 'rib' has a few 'pegs', each of which is connected to a macromolecule in the presynaptic membrane, possibly a $\mathrm{Ca}^{2+}$ channel [81]. The SNARE complex must be a part of these structures. Proteins that constitute these structures need to be identified. It would be profitable to extend this type of study to various synaptic mutant embryos.

\section{Acknowledgements}

This work was supported by a grant-in-aid from the Ministry of Education, Science, Sports and Culture of Japan. I thank Jia-mei Hou and Tomonori Okamoto for assistance in creating the figures.

\section{References}

1 Shi S-H, Hayashi Y, Esteban JA, Malinow R: Subunit-specific rules governing AMPA receptor trafficking to synapses in hippocampal pyramidal neurons. Cell 2001;105:331-343.

2 Turrigiano GG: AMPA receptors unbound: Membrane cycling and synaptic plasticity. Neuron 2000;26:5-8

3 Südhof TC: The synaptic vesicle cycle: A cascade of protein-protein interactions. Nature 1995;375:645-653.

4 Sutton RB, Fassbauer D, Jahn R, Brunger AT: Crystal structure of a SNARE complex involved in synaptic exocytosis at $2.4 \AA$ resolution. Nature 1998:395:347-353.

5 Broadie K, Bate M: Innervation directs receptor synthesis and localization in Drosophila embryo synaptogenesis. Nature 1993;361:350 353.
6 Broadie K, Bate M: Development of the embryonic neuromuscular synapse of Drosophila melanogaster. J Neurosci 1993;13:144-166.

7 Broadie K, Bate M: Activity-dependent development of the neuromuscular synapse during Drosophila embryogenesis. Neuron 1993;11: 607-619.

8 Kidokoro Y, Nishikawa K: Miniature endplate currents at the newly formed neuromuscular junction in Drosophila embryos and larvae. Neurosci Res 1994;19:143-154.

9 Nishikawa K, Kidokoro Y: Junctional and extrajunctional glutamate receptor channels in Drosophila embryos and larvae. J Neurosci 1996;15:7905-7915
10 Simon SM, Llinás RR: Compartmentalization of the submembrane calcium activity during calcium influx and its significance in transmitter release. Biophys J 1985;48:485-498.

11 Adler EM, Augustine GJ, Duffy SN, Charlton MP: Alien intracellular calcium chelators attenuate neurotransmitter release at the squid synapse. J Neurosci 1991;11:1496-1507.

12 Roberts WM, Jacobs RA, Hudspeth AJ: Colocalization of ion channels involved in frequency selectivity and synaptic transmission at presynaptic active zones of hair cells. J Neurosci 1990;10:3664-3684.

13 Miledi R, Thies R: Tetanic and post-tetanic rise in frequency of miniature endplate potentials in low-calcium solutions. J Physiol 1971; 212:246-257. 
14 Delaney KR, Tank DW: A quantitative measurement of the dependence of short-term synaptic enhancement on presynaptic residual calcium. J Neurosci 1994;14:5885-5902.

15 Sweeney ST, Broadie K, Keane J, Niemann H, O'Kane CJ: Targeted expression of tetanus toxin light chain in Drosophila specifically eliminates synaptic transmission and causes behavioral defects. Neuron 1995; 14:341-351.

16 Deitcher DL, Ueda A, Stewart BA, Burgess RW, Kidokoro Y, Schwarz TL: Distinct requirements for evoked and spontaneous release of neurotransmitter are revealed by mutations in the Drosophila gene neuronal-synaptobrevin. J Neurosci 1998;18;2028-2039.

17 Yoshihara M, Ueda A, Zhang D, Deitcher DL, Schwarz TL, Kidokoro Y: Selective effects of neuronal-synaptobrevin mutations on transmitter release evoked by sustained versus transient $\mathrm{Ca}^{2+}$ increases and by cAMP. J Neurosci 1999 ; 19:2432-2441.

18 Broadie K, Prokop A, Bellen HJ, O'Kane CJ, Schulze KL, Sweeney ST: Syntaxin and synaptobrevin function downstream of vesicle docking in Drosophila. Neuron 1995;15:663-673.

19 Saitoe M, Schwarz TL, Umbach JA, Gundersen CB, Kidokoro Y: Absence of junctional glutamate receptor clusters in Drosophila mutants lacking spontaneous transmitter release. Science 2001;293:514-517.

20 Kidokoro Y, Suzuki K: Multiple defects in synaptic transmission in Drosophila synaptotagmin-null mutant embryos. Abstracts from 'Neurobiology of Drosophila', Cold Spring Harbor Laboratory Meeting, Cold Spring Harbor, 2001, p 32.

21 Aravamudan B, Fergestad T, Davis WS, Rodesch C, Broadie K: Drosophila Unc-13 is essential for synaptic transmission. Nat Neurosci 1999;2:965-971.

22 Suzuki K, Okamoto T, Kidokoro Y: Biphasic modulation of synaptic transmission by hypertonicity at the embryonic Drosophila neuromuscular junction. J Physiol 2002;545:119131.

23 Fatt P, Katz B: Spontaneous subthreshold activity at the motor nerve endings. J Physiol 1952;117:109-128.

24 Rosenmund C, Stevens CF: Definition of the readily releasable pool of vesicles at hippocampal synapses. Neuron 1996;16:1197-1207.

25 Mochida S, Yokoyama CT, Kim DK, Itoh K, Catterall WA: Evidence for a voltage-dependent enhancement of neuromuscular release mediated via the synaptic protein interaction site of N-type $\mathrm{Ca}^{2+}$ channels. Proc Natl Acad Sci USA 1998;95:14523-14528.

26 Kashani A, Chen B-M, Grinnell AD: Hypertonic enhancement of transmitter release from frog motor nerve terminals: $\mathrm{Ca}^{2+}$ independence and role of integrins. J Physiol 2001;530:243252.

27 Suzuki K, Grinnell AD, Kidokoro Y: Hypertonicity-induced transmitter release at Drosophila neuromuscular junctions is partly mediated by integrins and cAMP/protein kinase A. J Physiol 2002;538:103-119.
28 Lane ME, Kalderon D: Genetic investigation of cAMP-dependent protein kinase function in Drosophila development. Genes Dev 1993;7: 1229-1243.

29 Byers D, Davis RL, Kiger JA Jr: Defect in cyclic AMP phosphodiesterase due to the dunce mutation of learning in Drosophila melanogaster. Nature 1981;289:79-81.

30 Yoshihara M, Suzuki K, Kidokoro Y: Two independent pathways mediated by cAMP enhance spontaneous transmitter release at Drosophila neuromuscular junctions. J Neurosci 2000; 15:8315-8322.

31 Zhang D, Kuromi H, Kidokoro Y: Activation of metabotropic glutamate receptors enhances synaptic transmission at the Drosophila neuromuscular junction. Neuropharmacology 1999; 38:645-657.

32 Meldolesi J, Scheer H, Madeddu L, Wanke E: Mechanism of action of $\alpha$-latrotoxin: The presynaptic stimulatory toxin of the black widow spider venom. Trends Pharmacol Sci 1986;7: 151-155

33 Chin AC, Burgess RW, Wong BR, Schwarz TL, Scheller RH: Differential expression of transcripts from $s y b$, a Drosophila melanogaster gene encoding VAMP (synaptobrevin) that is abundant in non-neuronal cells. Gene 1993; 131:175-181.

34 DiAntonio A, Burgess RW, Chin AC, Deitcher DL, Scheller RH, Schwarz TL: Identification and characterization of Drosophila genes for synaptic vesicle proteins. J Neurosci 1993;13: 4924-4935.

35 Rao SS, Stewart BA, Rivilin PK, Vilinsky I, Watson BO, Lang C, Boulianne G, Salpeter MM, Deitcher DL: Two distinct effects on neurotransmission in a temperature-sensitive SNAP-25 mutant. EMBO J 2001;20:67616771.

36 Capogna M, McKinney RA, O’Conner V, Gähwiler $\mathrm{BH}$, Thompson $\mathrm{SM}: \mathrm{Ca}^{2+}$ or $\mathrm{Sr}^{2+}$ partially rescues synaptic transmission in hippocampal cultures treated with botulinum toxin $\mathrm{A}$ and $\mathrm{C}$, but not tetanus toxin. J Neurosci 1997;17: 7190-7202.

37 Binz T, Blasi J, Yamasaki S, Baumeister A, Link E, Südhof TC, Jahn R, Niemann H: Proteolysis of SNAP-25 by types E and A botulinal neurotoxins. J Biol Chem 1994;269:16171620.

38 Washbourne P, Thompson PM, Carta M, Costa ET, Mathews JR, Lopez-Bendito G, Molnar Z, Becher MW, Valenzuela CF, Patridge LD, Wilson MC: Genetic ablation of the t-SNARE SNAP-25 distinguishes mechanisms of neuroexocytosis. Nat Neurosci 2002;5:19-26.

39 Zhong H, Yokoyama CT, Scheuer T, Catterall WA: Reciprocal regulation of P/Q-type $\mathrm{Ca}^{2+}$ channels by SNAP-25, syntaxin and synaptotagmin. Nat Neurosci 1999;2:939-941.

40 Schulze KL, Broadie K, Perin MS, Bellen HJ: Genetic and electrophysiological studies of Drosophila syntaxin-1A demonstrate its role in non-neuronal secretory processes and its essential role in neuromuscular release. Cell 1995; 80:311-320.
41 Burgess RW, Deitcher DL, Schwarz TL: The synaptic protein syntaxin 1 is required for cellularization of Drosophila embryos. J Cell Biol 1997;138:861-875.

42 Bennett MK, Calakos N, Scheller RH: Syntaxin: A synaptic protein implicated in docking of synaptic vesicles at presynaptic active zones. Science 1992;257:255-259.

43 Featherstone EE, Rushton EM, HildebrandChae M, Phillips AM, Jackson FR, Broadie K: Presynaptic glutamic acid decarboxylase is required for induction of the postsynaptic receptor field at a glutamatergic synapse. Neuron 2000;27:71-84.

44 Saitoe M, Schwarz TL, Umbach JA, Gundersen CB, Kidokoro Y: Response: Meaningless minis? Trends Neurosci 2002;25;385-386.

45 Bezprozvanny I, Zhong P, Scheller RH, Tsien RW: Molecular determinants of the functional interaction between syntaxin and $\mathrm{N}$-type $\mathrm{Ca}^{2+}$ channel gating. Proc Natl Acad Sci USA 2000; 97:13943-13948.

46 Wu MN, Fergestad T, Lloyd TE, He Y, Broadie $\mathrm{K}$, Bellen HJ: Syntaxin 1A interacts with multiple exocytotic proteins to regulate neurotransmitter release in vivo. Neuron 1999;23:593605.

47 Fergestad T, Wu MN, Schulze KL, Lloyd TE, Bellen HJ, Broadie K: Targeted mutations in the syntaxin $\mathrm{H} 3$ domain specifically disrupt SNARE complex function in synaptic transmission. J Neurosci 2001;21:9142-9150.

48 Broadie K, Bellen HJ, DiAntonio A, Littleton JT, Schwarz TL: Absence of synaptotagmin disrupts excitation-secretion coupling during synaptic transmission. Proc Natl Acad Sci USA 1994;91:10727-10731.

49 Schulze KL, Littleton JT, Salzberg A, Halachmi N, Stern M, Lev Z, Bellen HJ: rop, a Drosophila homolog of yeast Sec1 and vertebrate $\mathrm{n}$-Sec1/Munc-18 proteins, is a negative regulator of neurotransmitter release in vivo. Neuron 1994;13:1099-1108.

50 Bezprozvanny I, Scheller RH, Tsien RW: Functional impact of syntaxin on gating of $\mathrm{N}$ type and Q-type calcium channels. Nature 1995;378:623-626.

51 Rettig J, Heinemann C, Ashery U, Sheng Z-H, Yokoyama CT, Catterall WA, Neher E: Alteration of $\mathrm{Ca}^{2+}$ dependence of neurotransmitter release by disruption of $\mathrm{Ca}^{2+}$ channel/syntaxin interaction. J Neurosci 1997; 17:6647-6656.

52 Chapman ER, Desai R, Davis AF, Tornhel C: Delineation of the oligomerization, AP-2 and synprint-binding region of the $\mathrm{C} 2 \mathrm{~B}$-domain of synaptotagmin. J Biol Chem 1998;273:3296632972.

53 Südhof TC, Rizo J: Synaptotagmins: C2-domain proteins that regulate membrane traffic. Neuron 1996;17:379-388.

54 Littleton JT, Stern M, Perin M, Bellen HJ: Calcium dependence of neurotransmitter release and rate of spontaneous vesicle fusions are altered in Drosophila synaptotagmin mutants. Proc Natl Acad Sci USA 1994;91:1088810892. 
55 Littleton JT, Bellen HJ, Perin MS: Expression of synaptotagmin in Drosophila reveals transport and localization of synaptic vesicles to the synapse. Development 1993;118:1077-1088.

56 DiAntonio A, Schwarz TL: The effect on synaptic physiology of synaptotagmin mutations in Drosophila. Neuron 1994;12:909-920.

57 Popov SV, Poo M-M: Synaptotagmin: A calcium-sensitive inhibitor of exocytosis? Cell 1993;73:1247-1249.

58 Geppert M, Goda Y, Hammer RE, Li C, Rosahl TW, Stevens CF, Südhof TC: Synaptotagmin I: A major $\mathrm{Ca}^{2+}$ sensor for transmitter release at a central synapse. Cell 1994;79:717727.

59 Desai R, Vyas B, Earles C, Littleton JT, Kowalchyck J, Martin TFJ, Chapman ER: The C2B domain of synaptotagmin is a $\mathrm{Ca}^{2+}$ sensing module essential for exocytosis. J Cell Biol 2000;150:1125-1135.

60 Littleton JT, Bai J, Vyas B, Desai R, Baltus RD, Garment MB, Carlson SD, Ganetzky B, Chapman ER: synaptotagmin mutants reveal essential functions for the $\mathrm{C} 2 \mathrm{~B}$ domain in $\mathrm{Ca}^{2+}$ triggered fusion and recycling of synaptic vesicles in vivo. J Neurosci 2001;21:1421-1433.

61 Reist EN, Buchanan J, Li J, DiAntonio A, Buxton EM, Schwarz TL: Morphologically docked synaptic vesicles are reduced in synaptotagmin mutants of Drosophila. J Neurosci 1998;18: 7662-7673

62 Littleton JT, Serano TL, Rubin GM, Ganetzky B, Chapman ER: Synaptic function modulated by changes in the ratio of synaptotagmin I and IV. Nature 1999;400:757-760.

63 Robinson IM, Ranjan R, Schwarz TL: Synaptotagmin I and IV promote transmitter release independently of $\mathrm{Ca}^{2+}$ binding in the $\mathrm{C}_{2} \mathrm{~A}$ domain. Nature 2002;418:336-340.
64 Mackler JM, Drummond JA, Loewen CA, Robinson IM, Reist NE: The $\mathrm{C}_{2} \mathrm{~B} \mathrm{Ca}^{2+}$-binding motif of synaptotagmin is required for synaptic transmission in vivo. Nature 2002;418:340344.

65 Jorgensen EM, Hartwieg E, Schuske K, Nonet ML, Jin Y, Horvitz HR: Defective recycling of synaptic vesicles in synaptotagmin mutants of Caenorhabditis elegans. 1995;378:196-199.

66 Zhang JZ, Davletov BA, Südhof TC, Anderson RG: Synaptotagmin I is a high-affinity receptor for clathrin AP-2: Implications for membrane recycling. Cell 1994;78:751-760.

67 Fukuda M, Moreira JE, Liu V, Sugimori M, Mikoshiba K, Llinás RR: Role of the conserved WHXL motif in the $\mathrm{C}$ terminus of synaptotagmin in synaptic vesicle docking. Proc Natl Acad Sci USA 2000;97:14715-14719.

68 Fernández-Chacón R, Königstorfer A, Gerber SH, Garcia J, Matos MF, Stevens CF, Brose N, Rosenmund C, Südhof TC: Synaptotagmin I functions as a calcium regulator of release probability. Nature 2001;410:41-49.

69 Nonet ML, Grundahl K, Meyer BJ, Rand JB: Synaptic function is impaired but not eliminated in $C$. elegans mutants lacking synaptotagmin. Cell 1993;73:1291-1305.

70 Johansen J, Halpern ME, Johansen KM, Keshishian H: Stereotypic morphology of glutamatergic synapses on identified muscle cells of Drosophila larvae. J Neurosci 1989;2:710725.

71 Adams MD, Celniker SE, Holt RA, Evans CA, et al: The genome sequence of Drosophila melanogaster. Science 2000;287:2185-2195.

72 Littleton JT, Bellen HJ: Presynaptic proteins involved in exocytosis in Drosophila melanogaster: A genetic analysis. Invert Neurosci 1995;1:3-13.

73 Brand AH, Perrimon N: Targeted gene expression as a means of altering cell fates and generating dominant phenotypes. Development 1993; 118:401-415.
74 Lis JT, Simon JA, Sutton CA: New heat shock puffs and beta-galactosidase activity resulting from transformation of Drosophila with an hsp70-lacZ hybrid gene. Cell 1983;35:403410.

75 Delgado R, Maureira C, Oliva C, Kidokoro Y, Labarca P: Size of vesicle pools, rates of mobilization, and recycling at neuromuscular synapses of a Drosophila mutant, shibire. Neuron 2000;28:942-953.

76 McMahan UJ: The agrin hypothesis. Cold Spring Harb Symp Quant Biol 1990;55:407418.

77 Kidokoro Y, Yeh E: Initial synaptic transmission at the growth cone in Xenopus nerve-muscle cultures. Proc Natl Acad Sci USA 1982;79: 6732-6731.

78 Li L, Schwarz TL: Genetic evidence for an equilibrium between docked and undocked vesicles. Philos Trans R Soc Lond B Biol Sci 1999;354:299-306.

79 Jahn R, Südhof TC: Synaptic vesicles and exocytosis. Annu Rev Neurosci 1994;17:219-246.

80 Martin TFJ: Prime movers of synaptic vesicle exocytosis. Neuron 2002;34:9-12.

81 Harlow ML, Ress D, Stoschek A, Marshall RM, McMahan UJ: The architecture of active zone material at the frog's neuromuscular junction. Nature 2001;409:479-484.

82 Mogami K, O'Donnell PT, Bernstein SI, Wright TR, Emerson CP Jr: Mutations of the Drosophila myosin heavy-chain gene: Effects on transcription, myosin accumulation, and muscle function. Proc Natl Acad Sci USA 1986;84:1393-1397.

83 Stewart BA, Atwood HL, Renger JJ, Wang J, Wu CF: Improved stability of Drosophila larval neuromuscular preparations in haemolymphlike physiological solutions. J Comp Physiol [A] 1994;175:179-191. 